\section{International Scientific Journal Theoretical \& Applied Science}

p-ISSN: 2308-4944 (print) e-ISSN: 2409-0085 (online)

Year: $2018 \quad$ Issue: $01 \quad$ Volume: 57

Published: $30.01 .2018 \quad$ http://T-Science.org

SECTION 33 Advertising technologies.

Creative. Innovations.
Dmitry Olegovich Bordukh bachelor, Institute of Entrepreneurship and Sevice sector (branch) DSTU, g. Shakhty

Yury Dmitrievich Mishin Professor, candidate of philosophical Sciences, Department of "Philosophy and Culturology" of Siberian state transport University, Novosibirsk

Maria Valeryevna Reva the Department of "Private animal husbandry and feeding of farm animals" "Don state agrarian University" in the village of Persianovka, Rostov region

Vladimir Timofeevich Prokhorov Department of "Design,technology, and design" Institute of service sector and entrepreneurship in Shakhty, Rostov region

Stanislav Matveyevich Zverev JSC "Roslegprom" in city Moscow

Natalia Vasilievna Tikhonov

"Construction of clothes and shoes" Kazan National Research Technological University (Kazan,

Republic of Tatarstan, Russia)

\title{
LEARNING AS A FACTOR IN THE EDUCATION OF THE STAFF OF THE ENTERPRISE FOR THE PRODUCTION OF IMPORT- SUBSTITUTING PRODUCTS
}

\footnotetext{
Abstract: The authors investigated the value of learning for the formation of human behavior, capable of managing staff of the enterprise to provide satisfaction to himself the results of this work, to be smitten with her and become his face. For the successful management of the collective enterprise of research is needed to ascertain the degree of satisfaction of person with the results of the work of the collective enterprise with their work, i.e. to form rabotodatel. Then these people - people who love to work and willing to work well and are those who are able to implement the entire staff of the company formulated tasks, to ensure the production of import-substituting products.

Key words: specialization, standardization, performance, workaholics, the office, enterprise, enthusiasm, commitment, satisfaction, workload, salary, personality, identity, situation, compensation, risk, market, demand, competitiveness, products.

Language: Russian

Citation: Bordukh DO, Mishin YD, Reva MV, Prokhorov VT, Zverev SM, Tikhonov NV (2018) LEARNING AS A FACTOR IN THE EDUCATION OF THE STAFF OF THE ENTERPRISE FOR THE PRODUCTION OF IMPORT-SUBSTITUTING PRODUCTS. ISJ Theoretical \& Applied Science, 01 (57): 301-336.

Soi: http://s-o-i.org/1.1/TAS-01-57-45 Doi: croskef https://dx.doi.org/10.15863/TAS.2018.01.57.45

UDC685.34: 519.74

\section{НАУЧЕНИЕ КАК ФАКТОР ВОСПИТАНИЯ КОЛЛЕКТИВА ПРЕДПРИЯТИЯ ДЛЯ ПРОИЗВОДСТВА ИМПОРТОЗАМЕЩАЕМОЙ ПРОДУКЦИИ}

Аннотация: В статье авторы исследовали значение научения для формирования поведения человека, способного управлять коллективом предприятия, чтобы обеспечить себе удовлетворение себе результатами такой работы, быть увлеченным ею и стать его лицом. Для успешного управления коллектива предприятия необходимо проводить исследования с цеелью выяснения степени
} 
удовлетворенности человека результатами работь коллектива предприятия своей работой, т.е. формировать работоголиков. Тогда эти люди - люди, любящие работать и стремящиеся хорошо работать и будут теми, кто способен реализовать всему коллективу предприятия сформулированнье перед ним задачи, чтобы обеспечить производство импортозамещаемой продукции.

Ключевые слова: специиализация, стандартизация, производительность, работоголики, управление, коллектив предприятия, увлеченность, приверженность, удовлетворенность, объём выполненной работы, зарплата, индивидуальность, идентичность, ситуация, вознаграждение, риски, рынок, востребованность, конкурентоспособность, продукиия.

\section{Введение}

К критериальной основе поведения человека относятся те устойчивые характеристики его личности, которые определяют выбор, принятие решений человеком по поводу его поведения. Естественно, на данного рода решения оказывают большое влияние цели, которые преследует человек, условия, в которых разворачиваются действия, его возможности, динамика происходящих процессов, настроение и ряд других факторов. Однако при всем разнообразии факторов поведение каждого конкретного человека обладает определенной стабильностью и предсказуемостью, определенными присущими ему принципами поведения, критериями выбора и предпочтения, табу и тому подобными моментами. Более того, в совершенно одинаковых ситуациях, если только таковые вообще существуют, разные люди могут принять совершенно различные решения. И это опять будет определено тем, что они имеют различную критериальную базу, задающую их приоритеты и оценки происходящих событий.

Критериальная база поведения любого человека складывается из его расположения к людям, событиям и процессам, совокупности ценностей, разделяемых данным человеком, набора верований, которых придерживается человек, и принципов, которым он следует в своем поведении. Все эти составляющие критериальной базы поведения находятся в тесном взаимодействии, взаимопроникновении и взаимовлиянии. Однако, несмотря на сильную взаимозависимость, их можно рассматривать как относительно обособленные характеристики личности человека, влияющие на его поведение.

\section{Основная часть}

Расположение человека к людям, отдельным процессам, окружающей среде, своей работе, организации в целом играет очень большую роль в деле установления нормального взаимодействия человека и организационного окружения. Одно и то же явление или действие, имеющее совершенно одинаковое проявление и оказывающее одинаковое, влияние на людей, может вызвать различную реакцию в силу того, что у людей существует различное расположение к этому явлению или действию. Отражая чувства человека по отношению к определенному объекту, расположение делает его решения и действия индивидуальными. При этом важно подчеркнуть, что обычно человек имеет определенное расположение к каждому объекту или явлению, с которым он сталкивается в жизни.

Расположение характеризуется тем, что оно, во-первых, невидимо, так как заключено в человеке. На «поверхности» видны только его последствия. Во-вторых, расположение проистекает из тех чувств, которые питает человек к объекту. В-третьих, расположение как бы является точкой, находящейся на оси с полюсами «нравится» - «не нравится». Вчетвертых, расположение влияет на поведение человека и проявляется в том, что он ведет себя в соответствии с априорным положительным либо негативным отношением к явлению, объекту, процессу или человеку.

Допустимо ли в рамках научного анализа сравнение реального объекта с явлением из фольклорной классики, к примеру, рынка со сказочной пещерой Аладдина? Ответить на этот вопрос нелегко, так как мышление достаточно специализированно, а специализация закрепляется в определённых традициях, формализующих подход. Научное редактирование требует соблюдения требований характерного для науки способа изложения содержания мыслей. Неопозитивисты вообще пытались построить специальный язык научных коммуникаций, правда, безуспешно. Коллизия разрешалась практически, самими учеными, большинство из которых активно вовлекали в научные публикации образное мышление, справедливо полагая, что мышление представляет собой единый поток движения понятий и образов, логического и внелогического, реального и фантастического, воображаемого. Познание в любом выражении процесс поступательный, соединяет непрерывное с дискретным, обычное с необычным. Нормализованное мышление относительно, условно, организованно искусственно. Обращение в научном мышлении, включая его печатные формы, к образам, созданным вне научной специализации познания, естественно, обусловлено технологически.

Мышление не может существовать вне культуры, оно продукт культурного прогресса. Разнонаправленное развитие культуры - основа 
ее богатства, а противоречия культурного мышления диалектически едины. Сравнивая богатства сказочной пещеры с богатством развитого современного рынка, можно многое прояснить, как в экономическом познании, так и динамике трансформации экономической теории, в частности объяснить, почему современные ученые экономисты упорно дистанцируются от политического характера экономической науки, противопоставляя экономическую теорию классической политэкономии.

Воля, упорство, находчивость обеспечили Аладдину доступ к пещерным богатствам. Никакие хитросплетения не способны остановить целеустремленного человека. Нет непознаваемого, есть ещё непознанное. Рынок сложный экономический механизм, но и его можно понять и взять в управление. Богатства пещеры принадлежали насильникам, рынок также не свободен от насилия, поэтому государство обязано предпринимать необходимые меры обуздания рыночной стихии, служащей благодатной почвой для тех, кто предпочитает силу закону. Коренное же отличие богатств пещеры и рынка в том, что разбойники ничего больше не собирались добавлять, и Аладдин должен был довольствоваться полученным. Богатства же рынка, напротив, будут расти и вместе с ними проблемы, главная из которых реализация товарных поступлений. Каким должен быть товар, чтобы покупатель сметал его с полок? Какого покупателя хотели бы видеть на рынке?

Если «покупателя» рассматривать вне социально-экономического контекста, то ответ на второй вопрос выглядит предельно ясным. Рынок ждет покупателя с высокой платежеспособностью. Такие покупатели в России есть, однако их доля не превышает 7 процентов, и на привычный для масс рынок они редко ходят, скорее случайно, чем по необходимости. Массовый потребитель предельно экономен и «раскачать» его на покупку тяжело. Здесь требуется определённый вид товара, способный очаровать, и подача товара, - «культурная упакованность». Надо привлечь покупателя, заворожить. Как отражение стремления осмыслить специфику статуса востребованности товара на рынке нужно рассматривать оживление интереса к понятию «привлекательность товара». Оно существенно конкретнее по содержанию в сравнении с близким и более наукообразным понятием «востребованность товара рынком». В нем меньше экономической статистичности, формальных признаков, позволяющих измерять давление, но в полном объеме присутствует «человеческий фактор», определяющий рыночную динамику.
Понятие «привлекательность товара» конкретизирует в характеристике товара одновременно его потребительскую стоимость степень «обменности» на деньги и реалистичность цены, установленной продавцом. C понятием «привлекательность», обращенным векторно в сторону покупателя, приходится дружить и производителю, и продавцу. Оно связывает узлом интересы всех основных субъектов экономически свободного рынка. Данная функция «привлекательности» объясняет активное продвижение понятия в группу тех экономических категорий, которые раскрывают потенциал конкурентоспособности продукта на рынке. Это выдвижение отдельные авторы склонны трактовать как традиционные действия в интересах приложения рекламного производства, что делать нецелесообразно по причине односторонности, мешающей достижению системного понимания значения привлекательности товара в процессе воспроизводства. Рекламное производство действительно здесь присутствует, но в качестве сопровождающего фактора, то есть подтверждается обычное место рекламы на рынке.

Возрастающий интерес в научных исследованиях и экономической политике к понятию «привлекательность товара», на наш взгляд, показывает закономерность перестройки массового производства с существующего упрощенного типа к новому, иногда противопоставляемого ему, способу организации - lean production (рачительному, щадящему производству), ориентированному не на абстрактное многообразие потребностей покупателей, а на конкретную архитектонику потребительских запросов и платежеспособности потенциальных покупателей. Экономическую науку призывают через изучение архитектуры рынка сделаться непосредственной производительной силой, объективировать таким образом, основное последствие научнотехнической революции середины ХХстолетия.

История выделения рынка товаров в зону особого внимания экономистов и социологов сопряжена с рождением и развитием массового производства. Время массового фабричнозаводского производства исчисляют с Промышленной революцией, заложившей научно-технические и организационные предпосылки такого развития производительности труда, которое оказалось достаточным для реальной возможности удовлетворить спрос на жизненно значимые товары основной части населения посредством предоставления работы и устойчивой платы за труд. Именно это сочетание производства и потребления запустило развитие воспроизводства 
в национальных, а затем и транснациональных масштабах.

Предшествовавшее промышленному этапу натуральное хозяйство не соответствует в полной мере понятию «воспроизводство», оно определялось локальной востребованностью производимого продукта и было по существу замкнуто на производителя, не способствуя в должной степени национальному прогрессу. Отсюда и культ захватнических войн, нацеленных на грабеж ближних и дальних соседей, феодальная раздробленность, постоянный передел собственности. Войны и силовые акции выполняли функции рынка. Рынок работал в дополнение к политике, не был перманентным.

Уместно также подчеркнуть, что развитие рынка и формирование ставшего классическим образа воспроизводства, обязаны не только научно-техническому прогрессу, смене способа организации производства, но и конкуренции продуктов производства на рынке, дифференциации рыночной структуры. В истории рынка виден диалектический закон взаимосвязи количественных и качественных изменений. Когда производитель стал работать на рынок, продукт превратился в товар. Изменился статус продукта, поменялись и требования, предъявляемые к нему. Чтобы продукт был реализован по предназначению, он должен был привлечь к себе внимание покупателя. Товар это не продукт на продажу, а продукт, способный заинтересовать потребителя. Термин «ходовой товар» отражает как раз движение товара, его востребованность покупателем. «Ходовые товары» - локомотивы рынка.

Признак «привлекательности» принадлежит и к базовым характеристикам товара, и является «реликтовым» его свойством, укрепившим свои позиции. Непривлекательный товар производить непрофессионально, абсурдно. Домашних можно было заставить, приучить потреблять то, что заготовили, вырастили или изготовили, покупатели же имеют всегда свой резон и голосуют монетой, столь необходимой для продолжения производства.

В новейшее время синонимом «привлекательности» используется понятие «товарный вид». Отсюда, возможно, пошло выражение «видный товар», то есть тот, что аккумулирует к себе внимание, «бросается» в глаза. Умение сделать товар «видным», «привлекательным» требует и от производителя, и от продавца высокой квалификации, профессиональной фантазии, навыков презентации. Дело это затратное, но расходы окупаются результатом. Спрос на «привлекательный», «видный» товар высок, ускоряет получение оборотного капитала, стимулирует наращивание производства, консолидирует отношения продавца с производителем, придает прирастанию производства устойчивость, что служит хорошей рекламой производителю на рынке, избавляет от части прямых уплат рекламных услуг, обходящихся все дороже из-за своей вычурности.

Даже панорамно-историческое обозрение системного положения понятия «привлекательность» свидетельствует о его многогранности и сложности проявления. Тот факт, что термин «привлекательность» не столь часто встречается в журнальных публикациях, не должен вводить сознание в состояние вопроса относительно действительной значимости данного признака товарности в происходящей экономической перестройке на уровень lean production. Не случайно, отвечая на вопрос «Левада-центра», заданный в апреле 2017 года: «Что прежде всего внушает вам чувство гордости за Россию?», 1600 граждан страны из 137 населенных пунктов 48 регионов РФ «экономические успехи» поставили на предпоследнее место, отдав последнее «родственнице» - «системе здравоохранения».

К. Маркс начинал исследование буржуазного способа производства с анализа противоречивой природы товара. Товар объективно характеризуется наличием потребительской и меновой стоимости. Первая определяет его востребованность на рынке, вторая - меру такой востребованности. Стоимость объективирует трудовые затраты количество и качество произведенного труда. Труд также проявляется через противоречие, рожденное товарной сущностью капиталистического воспроизводства. С одной стороны, он есть созидательная, творящая сила человека, - грань его сущности, с другой, он с необходимостью отчуждает эту человеческую сущность, ибо продукт труда, вобравший в себя созидательную силу, производится для чужого потребления. Марксизм выводит из теории отчуждения социальный тупик развития буржуазного общества. В своем главном труде К. Маркс разрабатывал не только теорию развития капитализма, ему важно было довести до рабочего вида диалектико-материалистический метод научного анализа. Диалектика Г. Гегеля была локальной. Гегель ограничил диалектическое развитие движением духа. Маркс видел в диалектике универсальный способ развития, поэтому в «Капитале» обстоятельно проследил диалектику производства, сделав акцент на материальность природы товара, создаваемого трудом. Качество товара создается противоречивой природой товара и проявляется через отношение его в форме существенных признаков. Диалектический материализм 
опирается на признание материальности товара. Нематериальные товары - своего рода товарный полуфабрикат, «переходная форма» к практическому выражению, материализации. Однако материальность товара специфична.

Качество природных явлений действительно тождественно их материальной природе, но товар, даже в своей конечной формематериальности, есть нечто отличное от созданного вне и независимо от существования человека. Труд в товаре материализует разумную сущность человека - чувства, мысли, идеалы. В товаре выражается разумность человеческой реальности, следовательно в понятии «качество товара» должна быть запечатлена духовность человека, подтверждающая, что товар создается человеком для человека. На наш взгляд, рыночное качество товара призвано раскрывать единство стоимостей посредством сочетания естественной природы материала и искусственного еe преобразования творческой деятельностью человека. Качество товара, наряду с функциональностью, определяется его привлекательностью.

Привлекательность - высоко значимый фактор ценообразования. Часть цены, зависимая от привлекательности, может рассматриваться как экономический эквивалент привлекательности. Измеряется эта часть размером востребованности. Получение товара с новыми функциями затратно и ограниченно физической природой. Этот путь удивить потребителя сопряжен с риском снижения конкурентоспособности из-за высокой себестоимости. Проще и перспективнее манипулировать сознанием. Для этого есть готовые психологические механизмы и необходимые научные знания. Если товар в своем виде не произвел должного впечатления, не привлек, его можно сделать привлекательным, модулируя в определенном контексте, например, действуя на психику субкультурного восприятия. Сколько у нас эстрадных «звезд» без должных голоса и вокальной культуры. Мало того, что они привлекают своим исполнительским «мастерством», с них пытаются копировать одежду, аксессуары, обувь. Они формируют вкус определенных социальных групп, косвенно влияя на рыночное положение товаров. Нет данных поступить в государственные училища и вузы искусств, иди на «фабрики звезд».

«Привлекательность» обладает такими резервами, о которых у менеджеров еще весьма непрофессиональное представление. Нет сомнений, что в будущем маркетологи выйдут за пределы ныне определенного образованием спектра знаний и потеснят управляющих производством, ассортиментом. Управление рынком востребует не так, как ныне, учение 3.
Фрейда об «оно», «эго» и условиях достижения «суперэго»; теорию «коллективного бессознательного» К. Юнга; идеи Э. Фромма о значении для сознания способности удивляться и роли в реальной жизни сновидений.

Перспективы рынка и производства связаны с той активностью, которую управляющие проявят в отношении к понятию «привлекательность товара». Самым трудным для них окажется процесс перестройки мышления с утилитарного, прагматичного склада, сформированного парадигмой минимизации расходов для получения итоговой маржи, на новый принцип: получить законно и морально максимальную маржу. Всё энергичнее уходя в математическую методологию, экономисты утрачивают специфику политэкономического анализа, требующего действовать на фоне перспективы. Чаще нужно возвращаться к работам классиков - У. Петти, А. Смита, Д. Рикардо. «Классики» разбираясь в настоящем, думали о будущем, правильно полагая, что наука, ограниченная текущим ходом событий напоминает стоящий на якоре корабль, построенный как средство движения. «Отцы» экономической науки» были философами, их наследники скатились в бухгалтерский учет.

Экономистов можно понять. В условиях нестабильности мирового развития смотреть вперед дальше ближайшего угла крайне опасно. Кризис 2008 года, последствия которого до сих пор заставляют штормить мировую экономику, дело рукотворное. Путь прокладывали нобелевские лауреаты, хотели как лучше. Вышло, как всегда. Экономической науке пора вернуть мышлению масштабы - не только пространственные, но и временные. Исследования настоящего, проводить с заделом на разумно обозримую перспективу, комплексируя их со смежными науками, включая учение В.И. Вернадского о ноосфере. Э. Деминг еще в 1950-е годы, разрабатывая философские основания качества менеджмента, в разделе «Семь смертельных болезней» на первое место поставил планирование, не ориентированное на производство таких товаров и услуг, которые требуют рынок, при этом американский специалист сознавал сложность ситуации. [2]

Отсутствие достаточной для управления разработанности понятия «привлекательность товара» заставляет вспомнить его филологические корни, толкование «привлекательности» в классических источниках. В.И. Даль «привлекать» отождествлял с «притянуть», подчеркивал физический смысл термина, отодвигая на второй план физиологическую и психологическую стороны притягательности - «притягивать нравственно, чувством, силою убеждения..., манить, влечь, 
увлекать». [3, с.403] Ф. Брокгауз и И. Ефрон не включили в свое собрание этот термин. Обошла его и Britannica, что трудно оправдать, принимая во внимание стремление издания вносить в текст происходящие в мире изменения.

Обстоятельный анализ содержания понятия можно найти в четырехтомном Академическом Словаре русского языка. «Привлекательный, заманчивый, интересный.. который располагает к себе, возбуждает, пробуждает любознательность» [4, с.542]. Продолжая рассуждение о привлекательности, мы выйдем на признак «оригинальности». Обычно именно с оригинальностью, еe конкретностью, возбуждающей интерес к явлению, связывают привлекательность товара, что в общем соответствует представлениям. Вместе с тем, надо стараться не абсолютизировать положение «привлекательности» на товарном рынке.

Судьба товара на рынке определяется его востребованностью. «Востребованность» понятие социально-гуманитарного уровня. Оно обусловлено, с одной стороны, степенью развитости общества и платежеспособности массового потребителя, с другой - структурой потребностей покупателя. Эпикур дифференцировал потребности на основе двух признаков - естественности и необходимости. Согласно представлению античного мыслителя, потребности разделяются на три вида: «естественные и необходимые», «естественные и не необходимые» и «неестественные и не необходимые». [5, с.403, 469]

В суждениях Эпикура имеется подсказка к пониманию статуса товара. Есть товары объективно необходимые, их необходимость рождена естественной в них потребностью. Покупатель обязан такие товары купить - они необходимое условие его выживаемости. Конечно желательно, чтобы товары, составляющие «корзину существования» потребителя, были не только полезно необходимые, но и приятные по ощущениям, однако не приобрести подобные товары разрешается только в двух случаях, когда нечем заплатить и не на что поменять.

Естественно-необходимые товары «ходовые» на рынке всегда. Если они задерживаются на складах, либо в местах реализации, то причина одна - ценовая недоступность, жадность спекулянтов, оккупировавших рынок. Обувь - типичный представитель группы естественно-необходимых товаров, наравне с одеждой и бытовой утварью. Главная функция обуви заключена в еe способности защитить нижние конечности от механических и температурных повреждений. Дизайн обуви регламентирует прежде всего ее функциональной
Эстетическая сторона дизайна надстраивается над базисной функцией. Характерной особенностью обувных залов современных магазинов являются различного рода акции, направленные якобы на снижение цены. Когда третью пару обещают вручить бесплатно в торговом учреждении, это означает, что цена первой и второй позволяет безболезненно компенсировать потери, связанные с «подарком». Они оплачивают своей ценой «подарок». Более очевидного аргумента в пользу определения ситуации с ценообразованием как односторонней не существует. Нефтяники и газовики закладывают в ценообразование расходы на изыскания в сложных, нередко экстремальных обстоятельствах, требующих создания специального оборудования, специфических материалов. Неизведанное и неосвоенное сопряжено с высокими рисками, непрогнозируемыми научно-техническими потерями. Все понимают, что здесь присутствует спекулятивный подход, априорно завышающий потери на производство продукта, но отсутствие безупречно разработанных методик расчета неизбежных инвестиций в проектирование; уровень научно-технического обеспечения, необходимость рискованных действий, существенно смягчают критическую реакцию.

«На войне как на войне» назвал писательфронтовик, горевший в самоходке, свою известную повесть, экстраполируя его подход, повторим вслед: «На рынке как на рынке». Отпустив на свободу рыночные отношения между производителем товара, потребителемпокупателем и продавцом-посредником, власть облегчила жизнь себе и, не исключено, сделала ее безбедной за счет производителя и потребителя. Ценообразование в рыночном хозяйстве объективно предполагает участие таких факторов, как себестоимость товара, потребительская заинтересованность в нем покупателя, платежеспособность спроса и оплата участия продавца. Но речь идет о пропорциональном соучастии. Силу рыночных факторов нельзя рассчитать по формулам, описывающим силы в механическом движении, параллелограмма сил здесь не получить, однако пропорциональность соучастия в образовании итоговой цены получить можно с заданной степенью точности. И давно пора было эту операцию провести, чтобы политически и экономически определиться, где проходит граница цивилизованного рынка и базара, выстроенного «по понятиям».

За какую и чью рыночную свободу борются либералы - политики, почему перекосы в рыночном ценообразовании трактуются как естественные издержки развития, нормальные для демократического управления? Почему не 
совмещают пустые полки магазинов советского времени с очередями? Чтобы не было контраста с забитыми стеллажами нынешних магазинов и отсутствием покупателей? Дефицит действительно был до 1990-х годов, но связан он был в первую очередь с высоким уровнем покупательской способности, ценовой доступностью большинства товаров. Спрос опережал производство. Сейчас, напротив, предложения продавцов явно превосходят реальные возможности покупателей, что бьет больно и по отечественным производителям, так как торгуют привозимыми дешевыми товарами, опасными для здоровья.

Как следствие очередной политикоэкономической диспропорции процветает кредитование, создающее иллюзию покупательской способности. Российского потребителя экономической политикой загоняют в финансовую ловушку. Суть ситуации не в экономической безграмотности населения, а в мировоззренческом примитивизме, насаждаемом повсеместно и агрессивно. Школьников учат запоминать, студентов не учат научно мыслить, называя это модернизацией образования. Жизнь есть способность эффективно действовать, исходя из реальных возможностей. Подмена реальности действительно существующей, заработанной, на виртуально-предметную, жизнь взаймы, неизбежно ведет к духовному нигилизму, моральному разложению и кризису личности.

Первичные причины потребительской одномерности личности надо искать в анархии не выстроенного цивилизованно товарного рынка. Что дальше? Ответ надо искать там же, то есть там, где все с необходимостью встречаются - на рынке. Экономические приоритеты политики призваны определить роль рынка: сделается он братским захоронением родных производителей или пусковым механизмом подъема отечественного производства? Но и производители не должны созерцать происходящее, критиковать политиков и требовать для себя благоприятных условий развития. Они своим статусом в обществе поставлены перед жизненной необходимостью искать новые факторы продвижения, думать о резервах, еще не вовлеченных в процесс.

В замысле О. Конта о том, что каждая наука обязана быть философией, далеко не все ложно. Философы, придерживающиеся классических представлений о философии, спорили с Контом, считая ошибочным отдавать методологию и, особенно, мировоззрение на откуп частнонаучной рефлексии. Растворение философских размышлений в научном познании заведёт последнее в гносеологический тупик, так как спровоцирует абсолютизацию в решении универсальных проблем научного познания. Принятие обобщающих и направляющих решений в познании - удел независимого от специфики приватных суждений «судьи». В то же время, О. Конт был бесспорно прав, полагая, что только незасоренное стереотипами мышление способно действовать продуктивно, быть новаторским, инновационным, креативным. Тот, кто выдвинулся на путь организации развития бизнеса, как молитву №1 «Отче наш», обязан знать и повторять: только диалектическое мышление поможет мне быть успешным, спасет предприятие. Вот только кто в наши годы научит мыслить диалектически? Российские демократы, рулившие в политике конца ХX столетия, диалектику отождествляли $\mathrm{c}$ директивами и лозунгами советской эпохи и сознательно отрубали ей демократические корни также энергично, как выкорчевывали массандровские виноградники подручные М.С. Горбачева, а еще раньше поднимали целину строители коммунизма там, где это не следовало делать, по волюнтаристским указаниям Н.С. Хрущева.

Инициативный

предприниматель обусловлен в принятии решений состоянием и тенденциями существующего рынка. Но диалектически организованное мышление не позволит ему при разработке бизнес-плана, рассчитанного на обозримую перспективу, оказаться в тисках рыночной конъюнктуры. Каким бы произвольно образованным, анархически свободным рынок не был, он регулируется движением производства. Все в производстве связано общим узлом. «Все есть одно», утверждали античные диалектики, и искали то, что делает все единым. Рынок сегодня требует одно, завтра конъюнктура на нем будет другая, правда, нельзя исключить и повторения сегодняшнего. Поэтому нужен предварительный, комплексный, лучше системный, подход. Системный лучше, потому что позволяет приобщиться к сущности происходящего, предполагает выделение системообразующего фактора. Системообразующим фактором экономического анализа рыночного производства был и будет товар. Не случайно К. Маркс в «Капитале» начинал с товара, называл его клеточкой экономического организма капитализма и выстраивал из противоречивой природы товара противоречия движения буржуазного способа производства.

На рынке конкурируют не столько сами товары, сколько умы и воля производителей, разумеется оснащенных капиталами. Товары видимая сторона рынка, объективирующая в конкретных физических формах и действиях силу предпринимательского духа. Здесь мы вынуждены вновь обратиться к диалектике, ее требованию искать источник развития в 
противоречиях и не удивляться превращениям противоположностей, духа - в материальное, материальное - в духовное. Фундаментальный и универсальный вывод диалектики о конкретности истины разъясняет: то, что истинно сейчас, сделается заблуждением потом. Когда? Закономерно возникает вопрос. Ответ надо искать в тенденциях движения. Начинать же обязательно со всестороннего исследования того, из чего все. Для нас - это товар, его необходимые и дополнительные (надстроечные) признаки.

Производство товара обусловлено рынком. Когда-то рынок формировался за счет избыточного продукта и проявлялся в форме ярмарок. Сейчас товар изготавливают под потребности рынка. Рынок же, в свою очередь, аккумулирует в реальном выражении покупательские потребности. Случайно на рынке появляются антикварные продукты или что-то очень необычно новое. Теоретически, беря в расчет разумность человеческой деятельности, ее рациональность, взаимный интерес изготовителя, продавца и покупателя, можно допустить вывод, согласно которому все товары найдут своего потребителя. Если на рынке будут накапливаться нереализованные товары, он потеряет свою функцию и умрет как рынок - место купли и продажи. Практически так оно иногда и происходит. Только рынок не есть нечто абстрактное, существующее вне времени. Он представляет форму конкретно-временной реальности. На рынке особенно важен фактор времени.

Рынок - важнейшее звено, обеспечивающее своевременное воспроизводство товаров. Рыночные акции рождаются не из фантазии. Продавцы согласны нести определенные издержки, секвестировать в свои ожидания именно по причине необходимости сделать все вовремя. Иначе потери увеличатся, к финансовым издержкам присоединятся статусные. В зоне риска окажется авторитет самих субъектов рынка. В контексте данных рассуждений созревает мысль, что главная функция рынка не заставить вообще купить, а заставить купить как можно быстрее. Цивилизованно организованный рынок призван не только своевременно реализовать товар, но и быть фактором ускорения развития производства товаров. Как конкретно это можно осуществить?

Парадокс рынка состоит в том, что будущее рынка безоблачно, все проблемы рынка всегда современные, современными они останутся по мере разрешения одних и нарастания других. Откуда такая уверенность? Из анализа объективно реальных оснований истории рынка. Базисный рыночный товар тот, который обеспечивает естественно-необходимые потребности человека. Вне рынка удовлетворить то, без чего невозможно общественноиндивидуальное воспроизводство, нельзя. Рынок - общественно необходимое условие человеческой жизни и ее прогресса. Рынок должен не только быть, ему исторически вменяется быть фактором развития общества. Соответственно этому предназначению рынку положено быть в качестве развивающейся реальности, а обществу заботиться о развитии рынка. Не свободу давать «сколько способен заглотить» (Б.Н. Ельцин), а управлять свободой рынка в интересах рынка и его системного положения в общественном развитии.

Вернемся к видовой структуре товарного рынка и продолжим его анализ, отправляясь от исходной идеи о «базисном товаре». Удовлетворение с его помощью основных потребностей человека требует расшифровки с привлечением мировоззренческих достижений. Сделать можно и по-другому, упрощенно, только упрощение приведет к предупреждению «здравого смысла»: «простота хуже воровства». В экономическом анализе опасно что-либо недооценивать или переоценивать. Реальность человека дуалистична, вбирает в себя биологическое и социальное. В первом приближении разделить биологическое и социальное в человеке несложно.

Биологическое потребностей организма в питании, поддержании водно-солевого баланса и обмена, нормальности газообмена, защита температурных условий жизнедеятельности, воспроизводство потомства, перемещение в пространстве посредством самодвижения.

Социальное - удовлетворение условиями трудовой деятельности, развития мышления, сознания, речи, культурным прогрессом.

Биологическое и социальное сочетаются на основе потребности в общении и реализуются в общении посредством деятельности. Общественные и межличностные коммуникации также требуют своего рыночного выражения. Биологические и социальные особенности человеческой реальности многогранны. Они не заданы однажды и навсегда, прирастают, возникают синтетические формы проявления. Так что перспективы рынка естественнонеобходимых товаров и услуг обеспечены, как и рыночной конкуренции, следующей в фарватере своей функции способствовать массовой доступности покупателей $\quad$ п предлагаемой продукции.

Развитие рынка идет согласованно с развитием человека, его личностного выражения, новыми трендами социального движения. К традиционным секторам рынка XX век добавил спорт, научную деятельность, космос, кинематограф, международный туризм. Террор 
трансформировался в терроризм во многом благодаря проникновению на рынок. Рыночными услугами террористов активно пользуются США, региональные государства для укрепления своего политического положения. Особенно, когда подобные действия оказывают желательный эффект на традиционные рыночные и биржевые торги, к примеру углеводородами.

Развитие рынка идет в направлении возрастания его автономии. Этому вектору уделяют особое внимание представители финансового капитала, отлично сознающие, что рынок представляет оптимальные предпосылки для спекулятивных акций. Наконец, рынок в XX столетии стал любимым предметом экономической науки, стремящейся доказать, что в рынке сосредоточены силы движения экономики. Рынок стал символом новой экономики, её лидеры не против придать данному символу масштаб общественно-исторической значимости. Стремление представить современное общество как «общество потребления», «постиндустриальное общество» нужно понимать именно так.

Рынок не только место где спекуляция приобрела размер массового законного явления, он сам со временем сделался предметом спекуляции. Рыночная спекуляция и спекуляция на феномене рынка - объективная реальность, с необходимостью порождающаяся рынком, его, так сказать, обратные стороны, издержки развития.

Сколь бы не были значимы для истории рынка естественно - необходимые товары, гарантирующие устойчивость рыночного движения в обозримой перспективе, не надо переоценивать значимости их естественной необходимости. Естественная необходимость товарного ряда указывает на природу, характеризует существо предмета. Но природа и сущность товара непосредственно не выступают, они опосредуются явлением, преобразованной производством формой существования материала.

Низкие температуры, высокая влажность, необходимость защититься от травмы, соответствовать рабочему месту и специфике исполнения служебных обязанностей, приведут человека в магазин и сделают его потенциальным покупателем товара, которого ему не достает, но заставят приобрести лишь в одном случае, если ничего иного нигде не окажется.

Такая ситуация не совсем сказочная, однако выглядит несколько неправдоподобно для современной России. Выбор у нашего покупателя есть, как по цене, так и по привлекательности. 9 из 10 выбирают прежде всего по цене, исходя из содержимого кошелька, потом уже ориентируясь на удовлетворение эстетических претензий.
Продавцы могут не паниковать, никакой кризис не лишит рынок клиентов. Их проблема: у кого именно потребитель купит. Купит он то, в чем он увидит сочетание необходимости приобрести товар, свободных финансовых средств, точнее, цены на ценниках, и внешности товара, включая сюда искусство обслуживания. Формула покупки проста - «актуальность потребности плюс очаровательность предложения». Конкретным содержанием слагаемые должны наполнять специалисты, опираясь на опыт рыночных отношений. От себя напомним, что востребованность на ординарном, не эксклюзивном, авторском, рынке, бывает двух видов: естественная и искусственная, спровоцированная обещаниями производителей и рекламным процессом.

Отечественный потребитель, подсаженный на эффект «поп-культуры» «массмедиа», растерял самостоятельность вкуса вместе со способностью размышлять. Национальный колорит в значительной мере утрачен, процветает культ глобальности, рынок завален иностранным ширпотребом и контрафактной продукцией, к которой невозможно приложить качественную оценку.

На рынке складывается специфическая культурная картина, сложная для понимания. Культурой покупателя государство всерьез не интересуется. Прежний опыт культурного просвещения и воспитания изгнан. «Свято место пусто не бывает» и вместо государства пришли организации из структуры гражданского общества, у которых нет ни официальных полномочий, ни действенных механизмов, ни требуемых финансовых средств. Ученые экономисты убеждают предпринимателей, что нужно отсекать все, не входящее непосредственно в производство, сокращая расходы, повышая рентабельность. Поступая так, предприниматели загоняют себя в ловушку стихийности и капризов рыночной стихии, отказываясь от рычагов управления спросом.

«Рачительная экономка», приходящая на смену нынешнему нерационально устроенному массовому производству, ориентированному на абсолютизацию свободы выбора товара потребителем, когда ассортимент обязан удовлетворять запрос здесь и сейчас, иначе продавец потеряет клиентов и поставит под вопрос продолжение своего бизнеса, «завязана» на знание потребности конкретного покупателя. Разумеется такое знание специфично, оно ориентировочное, относительное, условное, больше похоже на знание предположение, но всетаки знание в отличие от абстрактной установки типа: покупатель пришел за товаром и он должен его купить, мы же обязаны ему помочь. Как конкретно? Не знаем, поэтому инициируем его 
желание ассортиментом. Определенная логика и этика в подобных размышлениях присутствуют. Сдерживает от поддержки цена этой логики высокий уровень издержек и нагрузки на естественную среду. Их ведь не спишут, распределят по потребителям, увеличив цену покупки.

«Привлекательность товара» способна стать магнитом, инициирующим интерес покупателя. Недаром В.И Даль толковал «привлекательность» как «притягательность», «магнетизм». Экономическая система формируется производственными отношениями, радикальных преобразований существующей системы экономики поэтому не будет, произойдет перестройка, перезагрузка, изменяющая не систему, а порядок функционирования системы, векторная эволюция экономической политики. Экономическая система пройдет оптимизацию путем рационализации затрат, минимизации расходов на ассортимент.

Выигрывает ли потребитель? Видимо, да, при условии, что производители и продавцы не поскупятся на исследовательские работы потребительского спроса. Здесь уже простейшими исследованиями не обойтись, потребуется глубокий анализ и комплексирование разных подходов экономического (маркетингового), социологического, культурологического, эргономического, сангигиенического, акцентирование научных исследований на региональные, национальные особенности. Откроется перспектива реального участия в процессе студентов разного уровня, ускоряя их квалификационное становление.

Переход от хорошего к лучшему в любой сфере деятельности сопряжен с увеличением затрат на осуществление, в том числе и финансирования рисков. В нашем представлении, анализируемый переход к новой экономической политике должен оправдать возлагаемые ожидания - привести к сокращению затрат, потерь, экологической нагрузки, но итог во многом будет он определятся построением научно-технической и образовательнопросветительской политики. Благие намерения нередко из-за, некачественного управления завершаются худшими результатами.

Дурной опыт прошлого описан даже в священных книгах. Модификация экономики массового производства в lean production предполагает мобилизацию научно-технической инициативы, максимального подключения культурных активов и реализации советского опыта просветительской работы в среде непосредственных потребностей конечного товара. Нелогично совершенствовать принципы и формы организации производства, рассчитанного на массовое потребление, без соответствующей подготовки потребителей. Прилагательное «массовый», вне зависимости от желаний, свидетельствует о включении деятельности в политический процесс, требующий и политического масштаба участия. Смена курса внутри экономической системы есть политический процесс с той спецификой, что он начинается в экономике.

Пришла вновь пора временно отключиться от производства товаров и, по примеру К. Маркса, сосредоточиться на клеточке современного экономического организма товаре, но, в отличие от автора «Капитала» поместить товар не в производство, а попытаться вписать его в подсистему рыночных отношений. Капитал без обращения не капитал. Капитал - это процесс. Процесс воспроизводства капитала характерный способ его существования. Рынок обеспечивает воспроизводство капитала, создавая условия реализации товарной продукции. Для производства необходим исходный капитал в финансовой форме, для реализации, как условия воспроизводства, требуется востребованность товара, которую должен обеспечить рынок условие, связывающие производителя с потребителем. Все, как видим, упирается даже не в характеристику товара, а в организацию рынка. Разумеется, и свойства товара здесь важны. Доктор способен реанимировать умирающего, но оживить труп не в состоянии. Тоже можно сказать и о рынке.

Что же касается культурной организации рынка, то ее стержнем рационально сделать работу с покупателем и производителем, реальным предметом (объектом) отношений, которых является товар, как совокупность свойств, способных удовлетворить всех субъектов рынка. Товар перейдет из собственности одного в собственность другого только при наличии консенсуса. Консенсус и призван обеспечить рынок. Консенсус - мера рыночной культуры.

Когда же на рынке перейдут от представления о консенсусе к пониманию консенсуса, рынок обретет статус «культурной организации». Можно ускорить этот процесс? Безусловно. Нужно организовать работу на обоих фронтах. И покупатель, и продавец должны быть подготовлены культурно к встрече на рынке. Выполнение действительной миссии рынка определяется качеством информационнонаучного его оснащения.

Социальная функция рынка удовлетворение социокультурных и естественнонеобходимых потребностей массового покупателя, способствуя тем самым национальному развитию и политическому прогрессу. Экономическая задача товарного 
рынка - вовлечь в производство финансовые резервы населения страны, а они немалые, реально сравнимые с годовым бюджетом России.

Управлять рынком возможно. Япония и Китай экономически различны, однако, несмотря на это, успешно управляют и производством и рынком. Управление рынком отличается от управления производством. Рынок сложнее устроен и разнонаправленно реагирует на стремление навести порядок. Порядки ведь тоже неоднородны. В театре один порядок, на скачках - другой, в казарме - третий. Управлять рынком можно (и желательно) экономически.

Конечный этап рыночных отношений реализация товара, следовательно управлять рынком следует через условия реализации товара, создавая благоприятные условия востребованности товара. Такое управление эффективно и в отношении потребителя, и производителя. Построение рынка по принципу: «здесь и сейчас покупатель должен удовлетворить свой запрос», экономит время и возможно незначительные финансовые средства потребителя, но противоестественно, ибо расточительно для общества и природы. Это «пижонство» по причине политической близорукости.

Не откажись от него, общество поставит в ответственное положение следующие поколения людей. Под вопросом окажутся будущее страны, народа.

Переход к производству, ориентированному рынком на структуру конкретизированного потребления, можно рассматривать как способ разрешения усиливающегося противоречия между растущими социокультурными потребностями и естественными источниками. И в этом смысле есть достаточно оснований говорить об объективной закономерности развития воспроизводства. Центр концентрации деятельности смещается на территорию рынка, актуализируется его научный потенциал. Вопрос №1 lean production: готов ли рынок к увеличению ассигнований на исследования структуры потребностей массового покупателя? Отдельные примеры найти нетрудно. Google в конце июня 2017 года провел опрос кулинарных предпочтений россиян с целью составить рейтинг базовых 20 продуктов и такого же количества блюд. Вкус российских потребителей обнадежил маркетологов и привел в ужас диетологов. Тем не менее, специалисты убеждены, что за два-три года изменений не произойдет. Производство, обеспечивающее продуктовый рынок, получило необходимую информацию к размышлению о направлениях инвестиций в производство. Теперь важно избежать ажиотажной перестройки, договориться о квотах внутри соответствующих союзов, ассоциаций и прочих объединений производителей.

Нас исследование известной фирмы заинтересовало в контексте задач общего плана, так как оно высветило несколько характерных оснований для размышления. Первое и, наверное, самое важное наводит на вывод о том, что экономисты-теоретики опять опоздали и вместо прогноза зафиксировали реальный факт существующей действительности. Рынок, обеспечивающий потребности массового покупателя, не был и неясно, когда будет соответствовать моделям маркетологов. Он сам себя формирует, приспосабливаясь к реалиям производства.

Отечественный покупатель на первое место поставил куриное яйцо, в середину отправил свинину и еще дальше молоко. Производство куриного мяса и яиц наладили еще в 1970-80-е годы, растеряли в 1990-е, спасая американских фермеров, вернулись позже к собственному хозяйству, быстро восстановили в нужных объемах. Рынок надежно обеспечен этой продукцией в ассортименте. Цены держатся, производитель, продавцы их не могут чрезмерно завышать - нет дефицита, создана сеть магазинов производителями. Разнообразный ассортимент, своевременное его пополнение, качественность, ценовая доступность продуктов формируют интерес к ним покупателя. Производство свинины также начали наращивать еще в дореформенное время, своеобразие выращивания свиного стада позволяет решать проблемы относительно быстро.

Сложнее всего с молоком. Рыночный либерализм больнее всего ударил по самому слабому звену сельхозпроизводства - молочному стаду. Оно и до девяностых было в массе в запущенном состоянии. Колхозы упразднили, фермерство, призванное поднять производство, не состоялось, как задумывали. Биология КРС такова, что нужного объема стада животных с удовлетворительными характеристиками следует ждать не менее 10 лет. Инвестиции требуются огромные! Запад не заинтересован в нас как конкуренте. Все перечисленное - это условия нестабильности и дефицита. Рынок сориентировался под дефицит и навел в кооперации с молокозаводами свой ценовой порядок. Молоко, доступное и качественное в трудные советские годы, стало и некачественным, и малодоступным рядовому массовому покупателю. Особенно изделия из молока. Потребителя рынок отучил от молока. Возникает вопрос. Почему? Рынок должен быть заинтересован в покупателе. Правильно, но в производстве и на рынке работают неглупые люди. Они понимают, что стадо КРС еще долго будут формировать. Неопределенное время 
получения результата достаточно, чтобы взять наибольшую маржу, а на массового потребителя рассчитывать не обязательно.

Второе, естественные и социокультурные потребности формируются стихийно только в самом общем, абстрактном виде. Конкретизируются же они в реальных условиях национального воспроизводства, на результатах экономической политики. Государство в состоянии воздействовать на этот процесс через контроль за производством и потреблением, разумеется, в соответствии с законами экономики.

C учетом сказанного можно попытаться сформулировать определение того, что такое расположение. При этом надо иметь в виду, что существует несколько различных взглядов на то, что такое расположение, и однозначного и совершенно четкого определения этого свойства личности дать невозможно.

В общем виде расположение можно определить как априорное отношение к человеку, группе людей, явлениям, организациям, процессам u вещяам, определяющее положительную или негативную реакцию на них.

Расположение имеет три компоненты. Вопервых, это та часть, которая отражает чувства человека по отношению к объекту: нравится ли он ему или нет. Данная часть называется воздействующей частью расположения. Вовторых, это знания об объекте, которыми располагает человек. В-третьих, это намерение по поводу того, как вести себя по отношению к объекту. Объединяясь вместе, эти три части формируют расположение человека к объекту, в котором находят динамическую увязку связи между знанием человека об объекте, его чувствами по отношению к этому объекту и его намерениями в отношении этого объекта.

Расположение человека по отношению к явлениям, процессам и людям формируется на основе обучения, базирующегося на жизненном опыте. Обычно положительное или отрицательное отношение к объекту формируется в результате того, вызывал ли данный объект удовлетворение или нет. При этом формирование расположения происходит как путем оценки опыта (удовлетворенность

неудовлетворенность) взаимодействия непосредственно с объектом, так и путем соотнесения объекта с другими объектами, по отношению к которым сформировалось определенное расположение.

Связь между поведением и расположением неоднозначна. Из того, что человек чего-то не любит, не вытекает на сто процентов факт, что он этого полностью не примет. Однако, тем не менее, в большинстве случаев поведение человека находится под влиянием расположения.
В связи с этим важной задачей управления является формирование и изменение, если это необходимо, расположения членов организации.

Важными для эффективного управления и установления хороших отношений в организации являются три. типа расположения:

$\square$ - удовлетворенность работой;

- увлеченность работой;

- приверженность организации.

То, насколько у работников развиты эти расположения, существенно определяет результаты их работы, количество прогулов, текучесть кадров и т.п.

Удовлетворенность работой оказывает очень сильное влияние на чувства человека по отношению к работе, поэтому ее можно отнести скорее к воздействующей компоненте расположения. Степень удовлетворенности работой зависит от множества факторов, как внутренних, так и внешних по отношению к человеку.

Однако при большом разнообразии факторов и различной направленности их влияния на человека выделяется восемь характеристик работы, от которых достаточно устойчиво зависит степень удовлетворенности работой:

$\square$ - характер и содержание работы;

$\square$ - объем выполняемой работы;

$\square$ - состояние рабочего места и его окружение (шум, освещенность, комфортность, температура воздуха и т.д.)

$\square$ - сослуживцы;

$\square$ - руководство (начальство, стиль руководства, участие в управлении);

$\square$ - оплата работы (все формы компенсации);

$\square$ - возможности продвижения по работе;

$\square$ - распорядок, правила поведения и т.п.

Данные характеристики носят достаточно общий характер. Применительно к каждой реальной работе они могут быть конкретизированы либо дополнены в зависимости от характера деятельности организации, ее характеристик и т.п. Практика показывает также, что приоритетность этих характеристик также может существенно различаться как у отдельных членов внутри организации, так и у различных организаций. И, наконец, в связи со стабильной удовлетворенностью отдельными характеристиками работы влияние на удовлетворенность работой со временем могут начинать оказывать новые или же ранее малозначимые характеристики работы. Поэтому для успешного управления и создания положительного расположения в отношении 
организации необходимо регулярно проводить исследования с целью выяснения степени удовлетворенности сотрудников организации своей работой.

Стабильно большое влияние на повышение удовлетворенности работой оказывает характер и содержание работы. Поэтому рассмотрим более подробно влияние отдельных составляющих этого фактора.

Длительное время стандартизациии $u$ специализация работы рассматривались и на практике выступали сильными источниками повышения производительности в работе. Чем выше стандартизация и специализация, тем выше производительность в работе. Однако зависимость между удовлетворенностью ею, и ее стандартизацией и специализацией носит иной характер. Если работа абсолютно не стандартизирована, то удовлетворенность работой находится на низком уровне. По мере увеличения специализации и стандартизации она начинает расти, но до определенного момента, после которого она начинает быстро снижаться. При полной стандартизации удовлетворенность падает до такого же низкого уровня как если бы работа была абсолютно не стандартизирована. Поэтому руководство должно думать, как снизить негативное влияние на удовлетворенность, работой, порождаемое чрезмерной специализацией и стандартизацией. Двумя наиболее распространенными способами осуществления этого являются ротация (перемещение работника с одного рабочего места на другое) и расширение производственных обязанностей путем постановки перед работником дополнительных задач.

Ясность содержания работы, ясность роли (особенно относительно содержания других ролей), наличие четкой обратной связи, информирующей индивида о результатах его работы в определенных обстоятельствах могут приводить к повышению удовлетворенности работой. В наибольшей мере это проявляется тогда, когда в организации существует четкое и формальное разграничение ролей.

Наличие элементов вызова в работе, таких, как творческое начало, возможность использования индивидом своих оригинальных или уникальных способностей, сложность заданий и т.п., приводит к повышению удовлетворенности работой. В то же время скучная работа, как это показывают исследования, обычно снижает удовлетворенность ею.

Увлеченность работой является одним из сильнейших расположений, определяющих то, как человек подходит к своей работе, к своему участию в процессе совместной работы. Развивается два типа увлеченности работой.
Один тип - это любовь к работе вообще, практически без учета того, чем конкретно заниматься. Людей с этим типом увлеченности называют работоголиками, т.е. людьми работающими, любящими работать и стремящимися работать. Данный тип расположения формируется воспитанием с детства, хотя и в более, позднем возрасте наблюдаются случаи развития этого расположения. Другой тип — это любовь к той конкретной работе, которую человек выполняет в организации. Оба эти типа не обязательно сопутствуют друг другу, хотя между ними и наблюдается большая взаимозависимость.

Для увлеченности работой характерно наличие трех аспектов. Во-первых, это то, насколько работа занимает существенное, центральное место в жизни человека (важность работы). Во-вторых, насколько работа сама по себе привлекает человека (рабочая сила). И, втретьих, насколько человек идентифицирует свою персоналию с выполняемой им работой (рабочая атрибутивность). Анализ по этим трем направлениям позволяет определить степень увлеченности человека своей работой. При этом необходимо принимать во внимание, что каждый из данных аспектов увлеченности работой является относительно самостоятельным и в зависимости от личностных особенностей человека может в разной степени влиять на его увлеченность работой.

Приверженность организации является расположением существенно более широким, чем увлеченность работой или же удовлетворенность работой. В современных условиях, когда все больше и больше организаций пытаются смотреть на человека не как на работника, выполняющего конкретную работу, а как на члена организации, стремящегося совместно с остальными ее членами привести организацию к достижению целей, значимость данного расположения становится исключительно высокой. Приверженность организации складывается из следующих составляющих. Вопервых, член организации разделяет и делает своими собственными цели организации и ее ценности. Во-вторых, член организации стремится оставаться в организации и сохраняет это стремление даже тогда, когда это может быть для него невыгодно. В-третьих, член организации готов не только стараться для организации, но и если это надо, принести в жертву организационным интересам свои личные.

Приверженность организации - личная особенность каждого конкретного человека. Однако это не значит, что менеджмент не может развивать или усиливать это расположение. Существует ряд приемов, способствующих этому. И наиболее успешные современные 
системы управления в очень большой степени базируются на том, что они развивают у работников сильную приверженность организации и добиваются благодаря этому очень больших успехов.

Ценности так же, как и расположение, оказывают сильное влияние на предпочтения человека, на принимаемые им решения и поведение в коллективе. Однако между ценностями и расположениями есть огромная разница. Если последние определяют отношение человека к объекту по принципу «нравится -— не нравится», «люблю - не люблю» и всегда относятся к какому-то определенному объекту, то ценности задают предпочтение человека по принципу «допустимо - недопустимо», «хорошо — плохо», «полезно - вредно» и т.П. При этом ценности носят достаточно абстрактный и обобщающий характер, живут «самостоятельной» жизнью, независимо от конкретного человека, сформулированы в виде заповедей, утверждений, мудростей, общих норм и могут разделяться большими группами людей. Поэтому, если расположение всегда сугубо персонально, то носителями ценностей являются группы людей (например, ценности среднего класса), а каждый отдельный человек принимает какой-то набор ценностей, который он может и менять, но которому он следует в каждый конкретный момент времени.

Ценности можно определить как набор стандартов и критериев, которым человек следует в своей жизни. Это проявляется в том, что путем соответствующей оценки происходящих вокруг него явлений, процессов и людей человек принимает решения и осуществляет свои действия.

Ценности составляют сердцевину личности человека. Они достаточно устойчивы во времени и их не так много. Обычно ценности рассматриваются как нормативная база морали и фундамент поведения человека. Ценности бывают двух видов:

- ценности, относящиеся к цели жизни, желаемым результатам, исходу действия и т.п.;

- ценности, относящиеся к средствам, используемым человеком для достижения целей.

К первому виду ценностей относятся, например, ценности, касающиеся удобства жизни, красоты, мира, равенства, свободы, справедливости, удовольствия, самоуважения, общественного признания, дружбы и т.п.

Ко второму виду ценностей относятся ценности, касающиеся амбиций, открытости, честности, доброжелательности, интеллектуальности, ответственности, самоконтроля и т.п.

Совокупность ценностей, которым следует человек, составляет его ценностную систему, по которой окружающие судят о том, что он представляет собой как личность.

Ценностная система человека формируется в основном в процессе его воспитания. Многие ценности человек получает под влиянием родителей и других близких ему людей. Большое влияние оказывают образовательная система, религия, литература, кинематограф и т.п.

Ценностная система подвергается развитию и изменению даже в зрелом возрасте. Большую роль в этом играет организационное окружение. В организациях, где серьезно думают о гармонии ценностей человека и ценностей организации, вопросам сочетания этих двух систем ценностей уделяется серьезное внимание. В частности, проводится большая работа по четкому формулированию, разъяснению и доведению до всех членов организации системы ценностей, которым следует организация. Значительное внимание уделяется также и уяснению того, какие ценностные ориентиры имеют члены организации.

Верования. Очень часто человек принимает решения на основе оценок явлений или заключений по поводу качеств этих явлений. Если данные оценки достаточно устойчивы и не требуют соответствующих доказательств, то они превращаются в верования. В общем виде верования можно определить как устойчивые представления о явлении, процессе или человеке, которые люди используют при их восприятии. Верования могут меняться во времени. Однако в тот момент, когда человек имеет какие-то определенные верования относительно объекта, он обычно воспринимает и. оценивает объект в соответствии с этими верованиями. По поводу одного и того же объекта может быть множество различных верований, так как обычно верования относятся к отдельным характеристикам объекта. Например, по поводу одного и того же человека могут быть следующие верования: 1) надёжный человек; 2) хороший специалист; 3) человек, обладающий слабым здоровьем и т.д.

Верования вырабатываются на основе индивидуального опыта, а также на основе информации, поступающей от внешних источников. Очень часто верования носят характер обобщения единичного опыта. Часто они возникают у человека в результате способностей других людей убеждать в правоте своего суждения, своего верования. Поэтому, хотя человек принимает свои верования за истину, они далеко не всегда полностью соответствуют действительности.

Верования могут быть разбиты на две большие группы.

Первую группу составляют описывающие абсолютные и относительные характеристики объекта верования, не имеющие оценочного 
характера. Например, автомобиль марки «Жигули» является комфортабельным автомобилем или автомобиль марки «Жигули» потребляет бензина меньше, чем автомобиль марки «Волга». Ко второй группе относятся те верования, которые носят оценочный характер. Например, автомобиль марки «Жигули» лучше, чем автомобиль марки «Волга». Верования оказывают заметное влияние на расположение, особенно на ту его составляющую, которая связана со знанием об объекте.

Особенно сильное влияние оказывает вторая группа верований. Поэтому, учитывая, что верования далеко не всегда соответствуют действительности, для того чтобы не формировалось неверное расположение по отношению к объекту, что может отрицательно сказаться на взаимодействии человека с окружением, необходимо критически и скептически подходить к своим верованиям и достаточно осторожно воспринимать верования других.

Принципы в жизни многих людей играют очень большую роль, так как они систематически регулируют их поведение. Принципы находят воплощение в устойчивых нормах поведения, ограничениях, табу, устойчивых формах реакции на явления, процессы и людей. Принципы формируются на основе системы ценностей, являются устойчивой формой проявления системы ценностей и воплощением верований в виде определенных стандартов поведения, Люди не обязательно осознают, какие ценности и верования находят свое воплощение в отдельных принципах. Часто принципы принимаются людьми как верования, и они следуют им в своей деятельности, не задаваясь вопросом по поводу оправданности следования этим принципам и почему они им следуют. Принципы могут вырабатываться людьми самостоятельно. Однако чаще всего они перенимаются из окружения вместе с воспитанием и другими формами познания окружающей действительности.

Влияние индивидуальности человека на управление предприятием для эффективности его деятельности.

Все люди в чем-то похожи друг на друга. И это позволяет говорить о человеке вообще, рассуждать о его чертах, особенностях поведения и т.П. Однако ни один конкретный человек не является обезличенным «человеком вообще». Каждый несет в себе что-то, что делает его уникальным, исключительным, т.е. человеком, обладающим индивидуальностью. Именно такой человек входит в организацию, именно такой человек выполняет определенную работу и играет определенную роль в организации, именно таким человеком нужно управлять, помогая ему раскрыть и задействовать свой потенциал в решении задач организации, создавая необходимые условия для его успешной работы, взаимодействия с организационным окружением и решения собственных жизненных проблем.

Индивидуальность человека складывается из трех начал. Во-первых, каждый человек в чемто сходен со всеми остальными. Во-вторых, каждый человек в чем-то одинаков с некоторыми другими индивидами. И, наконец в-третьих, каждый человек в чем-то не похож ни на кого. В зависимости от того, как сочетаются эти «начала» армируется индивидуальность каждого конкретного человека. При этом, как бы ни строилось это сочетание, нужно всегда помнить, что человек всегда одновременно имеет общее с остальными и не похож на остальных.

Каждый человек обладает устойчивым набором черт и характеристик, определяющих его действия и поведение. Данные черты проявляют себя в достаточно длительном промежутке времени, благодаря чему можно зафиксировать и почувствовать индивидуальность человека.

Конкретный человек фиксируется окружением по его индивидуальности, так как индивидуальность человека обладает определенной устойчивостью, люди узнают друг друга и сохраняют определенное отношение друг к другу. В то же время следует отметить, что под влиянием опыта, общения с другими людьми, воспитания и образования происходит изменение индивидуальности человека, иногда очень существенное.

Индивидуальность человека формируется под влиянием трех групп факторов. Первую группу составляют наследственность и физиологические особенности человека. Наследственность сохраняет и передает внешние черты человека. Но не только. Исследования, проводимые с близнецами, показывают, что наследственность может нести в себе и передачу некоторых поведенческих черт. Физиология человека говорит о том, что в людях очень много общего определяющего их поведение. В частности, одинаковым для всех является общий синдром адаптации, отражающий физиологическую реакцию на раздражение.

Вторую группу факторов, формирующих индивидуальность человека, составляют факторы, проистекающие из окружения человека. В общем виде влияние этих факторов можно рассматривать как влияние окружения на формирование индивидуальности. Во-первых, сильное влияние на индивидуальность человека оказывает культура, в которой он формируется. Человек получает от общества нормы поведения, 
усваивает под влиянием культуры определенные ценности и верования. Во-вторых, индивидуальность человека сильно определяется семьей, в которой он воспитывался. В семье дети усваивают определенные поведенческие стереотипы, вырабатываются их жизненные установки, отношение к труду, людям, своим обязанностями т.п. В-третьих, на индивидуальность человека оказывает сильное влияние принадлежность к определенным группами организациям, $\mathrm{y}$ человека вырабатываются определенная идентификация, задающая для него некий тип индивида, с которым он себя олицетворяет, а также устойчивые формы поведения и, в частности, реакции на воздействие со стороны окружения. В-четвертых, формирование индивидуальности происходит под влиянием жизненного опыта, отдельных обстоятельств, случайных событий и т.п. Иногда именно эта группа факторов может приводить к существенному изменению индивидуальности человека.

Третью группу факторов, влияющих на формирование индивидуальности человека, составляют черты и особенности характера человека, его индивидуальность. То есть в данном случае ситуация с формированием индивидуальности выглядит следующим образом: индивидуальность оказывает влияние на свое собственное формирование и развитие. Связано это с тем, что человек играет активную роль в собственном развитии и не является только исключительно продуктом наследственности и окружения.

При всей глубине индивидуальности человека и ее разнообразии можно выделить некоторые направления ее характеристики, по которым может быть описана индивидуальность.

Бывают люди, предпочитающие держаться на расстоянии от других, и это заметно сказывается на их поведении в коллективе. Люди с авторитарным характером считают, что должны быть порядок и различие в статусе и положении людей, стремятся к установлению иерархии отношений и использованию силовых методов в принятии решений и управлении, с готовностью признают власть и высоко ценят консервативные ценности. Любовь и вера в людей как индивидуальная черта характера оказывают сильное влияние на взаимодействие человека с окружающими. Особенно это проявляется в готовности участвовать в групповых мероприятия, способствовать развитию контактов, взаимодействий и взаимоподдержки.

Чувствительность к другим людям проявляется в способности людей сочувствовать другим, принимать близко к сердцу их проблемы, в умении поставить себя на место другого и т.п. Люди, обладающие такими чертами индивидуальности, хорошо воспринимаются в коллективе и стремятся к общению с людьми.

Стабильность в поведений человека играет большую роль в установлении его взаимоотношений с окружением. Если человек стабилен, ответствен и в целом предсказуем, то окружение воспринимает его положительно. Бели же он постоянно неуравновешен, капризен и склонен делать непредсказуемые шаги, то коллектив негативно реагирует на такого человека.

Самооценка, т.е. то, как люди смотрят на свое поведение, возможности, способности, внешность и т.п., оказывает сильное влияние на поведение человека. Люди с более высокой самооценкой обычно добиваются большего в жизни, так как они ставят перед собой более высокие Цели и стремятся решать более сложные задачи. В то же время люди с низкой самооценкой очень часто ставят себя в зависимое положение и легко подчиняются людям с более высокой самооценкой.

Восприятие риска является важной поведенческой характеристикой, наглядно отражающей индивидуальность человека. Люди, склонные к риску, меньше времени затрачивают на принятие решений и готовы принимать решения с меньшим количеством информации. При этом результат решения отнюдь не обязательно хуже, чем у тех, кто скрупулезно готовит решение и собирает всю необходимую информацию.

Догматизм обычно является чертой характера индивидов с ограниченным взглядом. Догматики видят окружение как сосредоточение угроз, ссылаются на авторитеты как на абсолюты и воспринимают людей по тому, как они относятся к догмам и абсолютным авторитетам. Обычно догматиками бывают люди, обладающие авторитарными чертами характера. Догматики не склонны к поиску большого объема информации, достаточно быстры в принятии решения, но при этом демонстрируют очень высокий уровень уверенности в аккуратности и правильности принятых решений. Отмечено, что догматики предпочитают работать в хорошо структурированных группах независимо от того, какую позицию они занимают в группе. Отмечено также, что догматики плохо осознают то, как они проводят свое время при выполнении работы, и то, что они слабо справляются с управленческой работой.

Комплексность осознания явлений как характеристика индивидуальности человека отражает его способность разлагать познаваемое явление на части и интегрировать, синтезировать общие представления или заключения об осознаваемом явлении. Люди с высокой комплексностью осознания проявляют большие 
способности к обработке информации, рассматривают большее количество альтернатив и принимают более комплексные решения, чем люди с низкой комлексностью осознания. Отмечено, что руководители с высокой комплексностью осознания в ситуациях с большим разнообразием среды лучше справляются со своими обязанностями, что этот тип руководителей более склонен к широким контактам с людьми, чем руководители с низким уровнем комплексности осознания, а также то, что данные руководители стремятся к использованию разнообразных ресурсов при решении задач.

Сфера, контроля отражает то, как индивид смотрит на источник факторов, определяющих его действия. Если человек считает, что его поведение зависит от него самого, то в этом случае для него характерно наличие внутренней сферы контроля (интроверты). Если же он считает, что все зависит от случая, внешних обстоятельств, действий других людей, то считается, что он имеет внешнюю сферу контроля (экстраверты). Интроверты лучше контролируют свои действия, более ориентированы на достижение результатов, более активны, более удовлетворены своей работой. Им нравится неформальный стиль управления, они любят воздействовать на других, но не любят воздействовать на себя, любят занимать руководящие позиции. Экстраверты же, наоборот, предпочитают формальные структуры, предпочитают работать под директивным руководством. Если же они занимают руководящие позиции, то широко используют методы силового воздействия.

Существует большое количество тестов и других инструментов, позволяющих определить характеристики индивидуальности человека. В современном менеджменте данным вопросам и данному виду деятельности уделяется огромное внимание. И связано это в первую очередь с тем, что успех организации напрямую зависит от того, насколько успешно она может задействовать весь имеющийся у нее в распоряжении человеческий потенциал.

Необходимость изучения индивидуальности человека вызывается также и тем, что обычно делается множество неверных заключений о людях, об их характеристиках, их индивидуальности. Связано это с тем, что люди при познании других опираются на стереотипы, предубеждения, необоснованные обобщения. Делая неверные выводы об индивидуальности людей, мы создаем основу для вредных конфликтов, скандалов, сплетен, трудностей в общении и взаимодействии людей. Это все наносит ущерб отдельным людям и организации в целом.
Факт необходимости тщательного и регулярного изучения индивидуальных характеристик членов организации не вызывает сомнения. Однако, признавая значимость и полезность этого вида управленческой деятельности, необходимо помнить и о том, что индивидуальность поведения человека зависит не только от его персональных черт, но и от ситуации, в которой осуществляются его действия. Поэтому изучение человека всегда должно вестись в совокупности с изучением ситуации.

Наконец, при изучении индивидуальности человека необходимо принимать во внимание его возраст. Человек проходит в своей жизни различные стадии, которым соответствует разное состояние его индивидуальности. Поэтому, делая выводы о характере человека, его персоналии, необходимо исходить из того, что его поведение очень сильно определяется тем, в какой возрастной стадии он находится. Только учет всех этих факторов в совокупности может дать ключ к пониманию индивидуальности человека, а следовательно, к управлению человеком.

\section{Влияние индивидуальности человека на его взаимодействие с коллективом предприятия}

Как уже говорилось выше, организация ожидает, что человек будет выполнять определенным образом роль, для которой она его принимает. Человек также смотрит на организацию как на место, где он получает определенную работу, выполняет ее и получает соответствующее вознаграждение от организации. Однако взаимодействие человека и организации не сводится только к ролевому взаимодействию. Оно гораздо шире. Человек выполняет работу в окружении людей, во взаимодействии с ними. Он не только исполнитель роли в организации, но и член группы, в рамках которой он действует. При этом группа оказывает огромное влияние на поведение человека. А поведение человека, его действия вносят определенный вклад в жизнь группы.

He существует канонизированного определения малой группы, так как это достаточно гибкое и подверженное влиянию обстоятельств явление. Однако широко принят достаточно общий, устоявшийся взгляд на малую группу (далее всегда термин «групnа» будет употребляться в этом смысле) как относительно обособленное объединение небольшого количества людей (обычно не более десяти двадцати пяти), находящиихся в достаточно устойчивом взаимодействии и осуществляющих совместные действия в течение достаточно 
долгого промежутка времени. Взаимодействие членов группы базируется на некоем общем интересе и может быть связано с достижением общей цели. При этом группа обладает определенным групповым потенциалом либо групповыми возможностями, позволяющими ей вступать во взаимодействие с окружением и адаптироваться к изменениям, происходящим в окружении.

Характерными особенностями группы являются следующие.

Bo-nepвblx, члены группы идентифицируют себя и свои действия с группой в целом и тем самым во внешних взаимодействиях выступают как бы от имени группы. Человек говорит не о себе, а о группе в целом, употребляя местоимения мы, у нас, наши, нам и т.н.

Bo-вторых, взаимодействие между членами группы носит характер непосредственных контактов, личного разговора, наблюдения поведения друг друга и т.п. В группе люди непосредственно общаются друг с другом, придавая формальным взаимодействиям «человеческую» форму.

B-mpeтьих, в группе наряду с формальным распределением ролей, если таковое существует, обязательно складывается неформальное распределение ролей, обычно признаваемое группой. Отдельные члены группы берут на себя роль генераторов идей, другие склонны к координации усилий членов группы, третьи заботятся о взаимоотношениях в группе, о поддержании хорошего климата в коллективе, четвертые следят за тем, чтобы был порядок в работе, все выполнялось в срок и доводилось до конца. Есть люди, которые исполняют роль структуризаторов, они ставят перед группой цели, отслеживают влияние окружения на решаемые группой задачи.

Эти и другие роли группового поведения люди выполняют в соответствии с их способностями и внутренним призванием. Поэтому в хорошо функционирующих группах обычно создаются возможности для того, чтобы человек мог вести себя в соответствии со своими способностями к групповым действиям и органично присущей ему определенной ролью члена группы.

Существует два типа групп: формальные $и$ неформальные. Оба эти типа групп имеют значение для организации и оказывают большое влияние на членов организации.

Формальные группы обычно выделяются как структурные подразделения в организации. Они имеют формально назначенного руководителя, формально определенную структуру ролей, должностей и позиций внутри группы, а также формально закрепленные за ними функции и задачи. Формальные группы могут быть сформированы для выполнения регулярной функции, как, например, бухгалтерия, а могут быть созданы для решения определенной целевой задачи, например, комиссия по разработке какого-либо проекта.

Неформальные группь создаются не распоряжениями руководства и формальными постановлениями, а членами организации в соответствии сих взаимными симпатиями, общими интересами, одинаковыми увлечениями, привычками и т.п. Данные группы существуют во всех организациях, хотя они не представлены в схемах, отражающих строение организации, ее структуру. Неформальные группы обычно имеют свои неписаные правила и нормы поведения, люди хорошо знают, кто входит в их неформальную группу, а кто нет, В неформальных, группах складывается определенное распределение ролей и позиций. Обычно эти группы имеют явно или неявно выраженного лидера. Во многих случаях неформальные группы могут оказывать на своих членов влияние, равное или даже большее! Чем формальные структуры.

Почему возникают группы, что заставляет людей формировать группы и входить в них? Данные вопросы очень важны для понимания поведения человека в организации. Очевидно, что группы возникают в организации и функционируют как обособленные структурные подразделения в связи с тем, что в результате разделения труда выделяются отдельные специализированные функции, требующие для своего выполнения определенной совокупности людей, обладающих определенной квалификацией, имеющих определенную профессию и готовых в системе совместной деятельности выполнять определенную работу. Аналогичная ситуация наблюдается при формировании групп, призванных решать целевые задачи.

Но это только одна сторона процесса появления групп в организации. Обычно она приводит к формированию формальных групп. Другой важной причиной формирования групп является естественное стремление человека к объединению с другими людьми, к формированию устойчивых форм взаимодействия с людьми. Группа дает человеку ощущение защищенности, от группы он ждет поддержки, помощи в решении своих задач и предостережения. В группе человеку легче добиться «вознаграждения» в виде признания, похвалы или же материального поощрения, В группе человек учится, перенимая опыт других, лучше осознавая свои возможности и потенциал. Группа придает человеку больше уверенности в себе во внешних взаимодействиях, способствует развитию его айдентити. * 
*данный термин отражает самосознание человека, его идентификацию себя с определенным стабильным явлением или состоянием.

Наконец, группа предоставляет человеку возможность препровождения времени в приятном для него окружении, возможность избежать одиночества и состояния потерянности, ненужности. Каждый человек стремится к тому, чтобы быть любимым кем-то, нужным кому-то, принадлежать кому-то, и группа может быть источником решения этих проблем человека.

О влиянии индивидуальности коллектива на эффективность управления предприятием

Независимо от типа группы, того, в какой организации она сформирована и функционирует, а также того, кто конкретно входит в группу, можно указать на некоторые общие моменты и факторы, характеризующие построение группы, еe структуру и процесс функционирования группы в ее окружении.

Жизнь группь, ее функционирование находится под влиянием трех факторов:

- характеристики членов группы;

- структурные характеристики группы;

- ситуационные характеристики.

Bсе эти факторы не только находятся во взаимодействии, взаимовлиянии, но и испытывают сильное обратное воздействие со стороны функционирования группы, так как в результате жизнедеятельности группы происходят изменения характеристик человека, изменяется построение группы и наблюдаются изменения в ее окружении.

K характеристикам членов группь, оказывающим влияние на ее функционирование, относятся личностные характеристики человека, а также способности, образование и жизненный опыт. Выше достаточно подробно были рассмотрены личностные характеристики

человека, поэтому мы не будем на них останавливаться в данном рассмотрении. Что касается остальных характеристик, то отмечено, что способности человека выполнять работу оказывают очень большое влияние на функционирование группы и на выполнение человеком своей роли. Также существенное влияние на группу оказывают уровень образования человека и его жизненный опыт.

Структурные характеристики группь включают в себя:

- коммуникации в группе и нормы поведения (кто с кем и как контактирует);

- статус и роли (кто занимает какую позицию в группе и что делает);

- личные симпатии и антипатии между членами группы (кто кому нравится и кто кого не любит);
- силу и конформизм (кто на кого оказывает влияние и кто за кем следует, кто кого готов слушать и кому подчиняться).

Первые две структурные характеристики группы относятся больше к организационной стороне анализа ее функционирования, поэтому они не будут рассмотрены здесь. Далее будут рассмотрены только структурные вопросы межличностных взаимодействий в группе.

Симпатии; и антипатии между людьми в основном носят индивидуальную окраску и подоплеку. Однако выяснено, что на установление дружеских отношений между людьми оказывают значительное влияние несколько моментов.

Bo-nервых, исключительно большое влияние оказывают личностные характеристики взаимодействующих. Люди любят тех, кому нравятся те же явления, вещи, процессы, которые нравятся им, т.е. люди любят тех, кто похож на них, кто близок им по духу, вкусу и предпочтениям. Естественно, существуют исключения. Однако исследования показывают, что люди испытывают влечение к тем, кто имеет одинаковую с ними или близкую расу, национальность, образование, систему взглядов на жизнь и т.п. Потенциально люди со схожими личностными характеристиками имеют большие шансы установить дружеские отношения, чем те, у кого личностные характеристики существенно различаются.

Bo-smopblx, на развитие и установление дружеских отношений между людьми, на развитие взаимной симпатии большое влияние оказывает наличие территориальной близости в расположении этих людей. Чем ближе располагаются рабочие места членов группы, тем выше вероятность того, что они установят дружеские отношения. Это же относится к близости расположения их мест жительства.

$B$-третьих, установление дружеских отношений находится в прямой зависимости от частоты встреч, а также от ожидания того, что эти встречи будут происходить достаточно часто в будущем.

$B$-четвертых, взаимоотношения между членами группы, их взаимные симпатии и антипатии, атмосфера дружественности в группе зависят от того, насколько успешно функционирование группы. В целом успех ведет к развитию у людей положительного отношения друг к другу в большей степени, чем неуспешное функционирование группы.

B-nятых, развитию дружеских отношений между членами группы способствует наличие одной цели, которой подчинены действия всех членов группы. Отмечено, что, если члены группы разобщены решением индивидуальных задач, взаимные симпатии и дружественность 
складываются реже, чем, если они работают над решением общей для всех задачи.

$B$-шестыx, положительная ориентация в отношении друг к другу возникает тогда, когда в группе практикуется широкое участие всех членов группы в принятии решения. Возможность оказывать влияние на обще групповые процессы стимулирует развитие у членов группы положительного восприятия группы.

Вне всякого сомнения, наличие симпатии в отношениях между людьми, наличие дружеских отношений между членами группы оказывает огромное влияние на настроение людей, на их удовлетворенность своей работой, своим членством в группе. Однако нельзя однозначно сказать, что дружеские отношения между членами группы оказывают только положительное влияние на результаты их труда и результаты функционирования группы в целом. Если люди, испытывающие дружеские отношения друг к другу, имеют высокую мотивацию к работе в группе, то наличие взаимных симпатий и дружбы способствует существенному повышению результатов их труда и тем самым положительно влияет на функционирование группы в целом. Если же эти люди слабо мотивированы на работу, то результат будет совершенно противоположным. Они много времени будут проводить в бесполезных для работы разговорах, перекурах, чаепитиях и т.п., постоянно отвлекаясь от работы и резко снижая результативность своей работы. При этом они могут отвлекать от работы других, создавая в группе атмосферу безделия и расслабленности.

Взаимная поддержка на базе симпатий и дружеских отношений, способствуя сплочению группы, может порождать синергический эффект, существенно повышающий результативность работы группы. Современная практика управления все более и более подтверждает наличие несомненных преимуществ у групповой формы организации труда перед индивидуальной. Наглядной иллюстрацией этого может служить, в частности, так называемый японский тип управления.

Однако при несомненном преимуществе перед другими формами организации работы, групповая форма может нести в себе и ряд отрицательных для организации моментов. Одним из таких негативных проявлений является групповщина, складывающаяся преимущественно на основе тесных отношений между членами группы, при условии, что в целом неверно поставлено управление группой и неверно организовано ее функционирование в организации.
Групповщина проявляется в том, что группа замыкается в самой себе, слабо и неверно реагирует на внешние сигналы, отрицает критику и т.п. Все это выражается в том, что, во-первых, в группе складывается тенденция морализации процессов, естественно, сопровождающаяся при этом представлением себя и своих действий в лучшем с моральной точки зрения свете. Вовторых, группа начинает ощущать себя неуязвимой и даже непобедимой в конфликтных столкновениях. В-третьих, в труппе складывается атмосфера конформизма, стремление заставить всех соглашаться с единым мнением, нежелание слушать и обсуждать другие мнения и точки зрения и т.п. В-четвертых, в группе развивается единодушие. Люди начинают все более мыслить, как остальные. И если даже у них возникают другие мнения, они не высказываются, так как сами сомневаются в них, считая, что общее мнение верно. В-пятых, группа перестает воспринимать и отказывается рассматривать мнения извне, если они не совпадают с мнением группы.

Сила и конформизм во взаимоотношениях между членами группы проявляются в виде так называемого общественного влияния на человека. Группа оказывает давление на человека, требуя от Него следования групповым нормам, правилам, требуя подчинения интересам группы. Человек может сопротивляться этому давлению, а может уступить группе — подчиниться, т.е. выступать конформистом.

Нельзя однозначно утверждать, что один тип отношений человека с группой верный, а другой нет. Очевидно, что конформизм может приводить к тому, что человек, даже осознавая неверность своих действий, осуществляет их, потому что группа делает это. Конформизм может превратить человека в бессловесный придаток группы. История человечества знает массу негативных примеров того, как «стадный инстинкт», или же, говоря по-другому, безоговорочный конформизм, лежал в основе страшных преступлений против отдельных людей и человечества в целом. Знает она примеры того, как группа полностью стирала личность человека, превращая его в винтик в групповом механизме. В то же время, очевидно, что без конформизма не может быть создано сплоченной группы, не может быть установлено баланса во взаимоотношениях между человеком и группой. Если человек стоит на жестких нонконформистских позициях, то он не сможет стать полноценным членом группы и на определенной стадии развития конфликта между ним и группой вынужден будет покинуть группу.

Так как конформизм во взаимоотношениях человека с группой, с одной стороны, выступает условием интеграции индивида в группу, а с 
другой - может порождать негативные последствия как для окружения, так и для группы в целом, и данного индивида в частности, важным является выяснение того, какие факторы и в какой мере требуют от члена группы делать уступки общественному влиянию.

Характер решаемых задач оказывает заметное влияние на степень конформизма в поведении человека. Если задачи четко не определяемы, если они не имеют однозначного ответа, то они заставляют человека, выполняющего их, больше поддаваться влиянию группы. Степень конформизма зависит также от того, выдавал ли член группы публичные обязательства по поводу решаемой задачи или нет, а также оттого, на какой стадии решения он заявил о своих обязательствах. Публичное и раннее заявления делают человека более подверженным общественному влиянию. Конформизм в поведении человека развивает оплату по результатам групповой работы.

Характеристика группь также оказывает большое влияние на развитие у человека конформизма по отношению к требованиям группы. Единодушие в групповом поведении усиливает степень влияния группы на человека. Человеку легче возразить или не соглашаться, если кто-то еще в группе имеет, мнение, отличное от группового. На конформизм в поведении человека в группе оказывает влияние численность группы. Если в группе пять человек, то единодушие начинает оказывать сильное влияние на индивида. Дальнейший рост численности группы слабо сказывается на увеличении влияния группы на человека. Степень конформизма в поведении человека в группе зависит также от близости руководства в групповых действиях и частоты контактов с руководством. Если начальник часто присутствует и участвует при принятии решений членом группы, то это приводит к повышению конформизма в поведении подчиненного.

Желание подчиняться влиянию со стороны группы, напрямую, зависит от личностных отношений между членами группы, их симпатий и антипатий, дружбы и т.п. Чем лучше личные отношения между членами группы, тем выше степень конформизма в их поведении в группе и тем выше возможность общественного влияния на членов группы.

Ситуационные характеристики группь мало зависят от поведения членов группы и группы в целом. Эти характеристики связаны с размером группы, еe пространственным расположением, задачами, решаемыми группой, и системой вознаграждения, применяемой в группе.

В малых по размеру группах возникает больше сложностей с достижением соглашения, и много времени уходит на выяснение отношений и точек зрения. В больших группах наблюдаются трудности с поиском информации, так как члены группы обычно ведут себя более сдержанно и концентрированно. Отмечено также, что в группах с четным числом членов, хотя и наблюдается больше напряженности с принятием решения, чем в группах с нечетным числом членов, тем не менее меньше несогласия и антагонизма между членами группы.

Размер группь также оказывает влияние на удовлетворенность работой. Отдельные исследования показывают, что люди более удовлетворены, если они работают в группе среднего размера (5-6 человек). Малые группы порождают много напряжений в отношениях между ее членами, а в большой не уделяется достаточно времени для каждого члена группы.

Пространственное расположение членов группы оказывает заметное влияние на их поведение. Одно дело, когда человек имеет постоянное место расположения, другое - когда он ищет каждый раз себе это место. Люди во время работы могут смотреть друг на друга, а могут быть расположены спиной друг к другу. И это также будет оказывать влияние на их работу и на их поведение в группе.

Выделяются три важные характеристики пространственного расположения индивида, от которых зависят взаимоотношения между человеком и группой.

Bo-nepвыx, это наличие постоянного или определенного места или территории. Человек знает: это мой стол, это мой станок, это мое рабочее место. Отсутствие ясности в данном вопросе порождает множество проблем и конфликтов в межличностных отношениях, а также значительно понижает удовлетворенность работой.

Bo-вторых, это личное пространство, т.е. то пространство, в котором находится тело только данного человека. Пространственная близость в размещении людей может порождать множество проблем, так как людьми не воспринимается близкое расположение к ним других людей без учета возраста, пола и т.п.

B-третьих, это взаимное расположение мест. Отмечено, что если рабочие места отгорожены друг от друга, то это способствует развитию формальных отношений. Наличие рабочего места руководителя группы в общем пространстве способствует активизации и консолидации группы. Если человек занимает рабочее место во главе стола, то это в глазах других членов группы автоматически ставит его в позицию лидера. Руководство, зная эти и другие вопросы расположения членов группы, может добиваться значительного эффекта и повышения 
результативности работы группы только за счет правильного размещения рабочих мест.

Влияние задач, решаемых группой, на функционирование группы и на поведение и взаимодействие членов группы очевидно. Однако очень сложно установить зависимость между типами задач и их влиянием на жизнь группы. Отмечено, что решение формальных задач, например математических, в меньшей мере способствует развитию отношений между членами группы, чем решение задач гуманитарного профиля. Известно, что задачи и функции, выполняемые группой, влияют на стиль руководства, а также на стиль общения между людьми. В случае слабо структурированных или неструктурированных задач наблюдается большее давление группы на индивида и большая взаимозависимость действий, чем в случае хорошо структурированных задач.

Можно указать на несколько характеристик задачи, на которые важно обращать внимание для того, чтобы попытаться определить как решение данной задачи будет влиять на группу в целом и на поведение ее членов.

Bo-nepвыx, надо определить, как много взаимодействий будет возникать между членами группы в процессе решения задачи и как часто они будут коммуницировать друг с другом.

Bo-вторых, надо выяснить, насколько действия, выполняемые отдельными людьми, взаимозависимы и оказывают взаимное влияние.

B-mpeтьих, важно установить, насколько решаемая задача является структурируемой.

Системы вознаграждения, рассматриваемые в отрыве от характера взаимоотношений в группе, не могут сами по себе дать ответа на вопрос о том, в какой мере та или иная система влияет на взаимоотношения в группе, поведение членов группы, функционирование группы в целом. Например, нельзя оценить влияние на группу индивидуально-сдельной оплаты, коллективносдельной оплаты или же оплаты на основе фиксированного бюджета группы, если не знать характера деятельности группы.

При анализе влияния оплаты важно учитывать одновременно две совокупности факторов:

насколько взаимозависимы действия членов группы;

насколько велика дифференциация в оплате.

Возможны четыре комбинации этих факторов:

- низкая взаимозависимость - низкая дифференциация в оплате;

- низкая взаимозависимость - высокая дифференциация в оплате;

высокая взаимозависимость-низкая дифференциация в оплате; высокая взаимозависимость - высокая дифференциация в оплате.

Первый и четвертый случаи порождают много проблем во взаимоотношениях между членами группы. Напротив, второй и третий случаи могут способствовать успешному функционированию группы и развитию благоприятных отношений между членами группы.

Взаимодействие человека и группы всегда носит двусторонний характер; человек своим трудом, своими действиями способствует решению групповых задач, но и группа оказывает большое влияние на человека, помогая ему удовлетворять его потребности безопасности, любви, уважения, самовыражения, формирования личности, устранения беспокойств и т.п. Отмечено, что в группах с хорошими взаимоотношениями, с активной внутригрупповой жизнью люди имеют лучшее здоровье и. лучшую мораль, они лучше защищены от внешних воздействий и работают эффективнее, чем люди, находящиеся в изолированном состоянии либо в «больных» группах, пораженных неразрешимыми конфликтами и нестабильностью. Группа защищает индивида, поддерживает его и обучает как умению выполнять задачи, так и нормам и правилам поведения в группе.

Но группа не только помогает человеку выживать и совершенствовать свои профессиональные качества. Она меняет его поведение, делая человека зачастую существенно отличным от того, каким он был, когда находился вне группы. Эти воздействия группы на человека имеют много проявлений. Укажем на некоторые существенные изменения в поведении человека, происходящие под влиянием группы.

Bo-nервых, под общественным влиянием происходят изменения таких характеристик человека, как восприятие, мотивация, сфера внимания, система оценок и т.д. Человек расширяет сферу своего внимания за счет усиления внимания к интересам других членов группы. Его жизнь оказывается в зависимости от действий его коллег, и это существенно меняет его взгляд на себя, на свое место в окружении и на окружающих.

Bo-вmopblx, в группе человек получает определенный относительный «вес». Группа не только распределяет задания и роли, но и определяет относительную позицию каждого. Члены группы могут делать совершенно одинаковую работу, но иметь при этом разный «вес» в группе. И это будет дополнительной существенной характеристикой для индивида, которой он не обладал и не мог обладать, находясь вне группы. Для многих членов группы 
эта характеристика может быть не менее важной, чем их формальная позиция.

B-mpeтьих, группа помогает индивиду обрести новое видение своего «я». Человек начинает идентифицировать себя с группой, и это приводит к существенным изменениям в его мировосприятии, в понимании своего места в мире и своего предназначения.

$B$-четвертых, находясь в группе, участвуя в обсуждениях и выработке решений, человек может выдать также предложения и идеи, которые он никогда не выдал бы, если бы осмысливал проблему в одиночку. Эффект воздействия на человека «мозговой атаки» существенно повышает творческий потенциал человека.

B-nяmblx, отмечено, что в группе человек гораздо в большей мере склонен принимать риск, чем в ситуации, когда он действует один. В ряде случаев эта особенность изменения поведения человека является источником более действенного и активного поведения людей в групповом окружении, чем, если бы они действовали в одиночку.

Неверно думать, что группа меняет человека так, как ей захочется. Часто многим воздействиям со стороны группы человек долго сопротивляется, многие воздействия он воспринимает только частично, некоторые он отрицает полностью. Процессы адаптации человека к группе и подстройки группы к человеку являются неоднозначными, сложными и зачастую достаточно длительными. Входя в группу, вступая во взаимодействие с групповым окружением, человек не только изменяется сам, но оказывает воздействие на группу, на других ее членов.

Находясь во взаимодействии с группой, человек пытается различными способами воздействовать на нее, вносить изменения в ее функционирование с тем, чтобы это было приемлемо для него, удобно ему и позволяло ему справляться со своими обязанностями. Естественно, и форма воздействия, и степень влияния человека на группу существенно зависят как от его личностных характеристик, его возможностей оказывать влияние, так и от характеристик группы. Человек обычно выражает свое отношение к группе с позиций того, что он считает. При этом его рассуждения всегда находятся в зависимости от той позиции, которую он занимает в группе, от выполняемой им роли, от возложенного на него задания и соответственно от того, какие цели и интересы он преследует сам лично.

Взаимодействие человека с группой может носить либо характер кооперации, либо слияния, либо конфликта. Для каждой формы взаимодействия может наблюдаться различная степень проявления. То есть, например, можно говорить о скрытом конфликте, о слабом конфликте или же о неразрешимом конфликте.

В случае кооперации между членом группы и группой устанавливаются доверительные и благожелательные отношения. Человек рассматривает цели группы как не противоречащие его целям, он готов к поиску путей улучшения взаимодействия, положительно, хотя и с переосмыслением собственных позиций, воспринимает решения группы и готов к поиску путей поддержания отношений с группой на взаимовыгодной основе.

При слиянии человека с группой наблюдается установление таких отношений между человеком и остальной частью группы, когда каждая из сторон рассматривает другую как органически единую с ней составляющую целого, являющегося группой. Человек строит свои цели исходя из целей группы, в значительной мере подчиняет свои интересы интересам группы и идентифицирует себя с группой. Группа, в свою очередь, также старается смотреть на индивида не как на исполнителя определенной роли, а как на полностью преданного группе человека. В этом случае группа берет на себя заботу о человеке, рассматривая его проблемы и трудности как свои, старается оказать ему содействие в решении не только производственных задач, но и в решении его личных проблем.

B случае конфликте наблюдаются противопоставление интересов человека и группы и борьба между ними за разрешение этого противоречия в свою пользу.

Конфликты могут быть порождены двумя группами факторов:

- организационными факторами,

- эмоциональными факторами.

Первая группа факторов связана с различием во взглядах на цели, структуру, взаимоотношения, распределение ролей в группе и т.н. Если конфликт порожден этими факторами, то его относительно легко разрешить.

Ко второй группе факторов относятся такие факторы, как недоверие человеку, чувство угрозы, страх, зависть, ненависть, злоба и т.п. Конфликты, порождаемые этими факторами, слабо поддаются полному устранению.

Конфликт между членом группы и группой неверно рассматривать только как неблагоприятное, негативное состояние отношений в группе. Оценка конфликта принципиально зависит от того, к каким последствиям для человека и группы он приводит. Если конфликт превращается в антагонистическое противоречие, разрешение которого носит разрушительный характер для человека или для группы, то такой конфликт 
должен быть отнесен к разряду нежелательных и отрицательных форм взаимоотношений человека и группы.

Но очень часто конфликт в отношениях внутри группы носит позитивный характер. И это связано с тем, что конфликт может привести к благоприятный последствиям.

Во-первых, конфликт может повысить мотивацию на достижение целей. Он может вызвать дополнительную энергию к действию, вывести группу из устойчивого пассивного состояния.

Во-вторых, конфликт может привести к лучшему пониманию отношений и позиций в группе* к уяснению членами их роли и места в группе, к более четкому пониманию задач и характера деятельности группы.

В-третьих, конфликт может играть созидательную роль в деле поиска новых путей функционирования группы, поиска новых подходов к решению задач группы, в генерировании новых идей и соображений относительно того, как строить отношения между членами группы, и т.п.

В-четвертых, конфликт может привести к проявлению межличностных отношений, к выявлению отношений между отдельными членами группы, что в свою очередь может предотвратить возможное негативное обострение отношений в будущем.

Одним из основных результатов взаимодействия человека и организации является то, что человек, анализируя и оценивая результаты своего труда в организации, вскрывая причины успехов и неуспехов во взаимодействии с организационным окружением, анализируя опыт и поведение своих коллег, задумываясь над советами и рекомендациями начальства и сослуживцев, делает для себя определенные выводы, которые в той или иной мере сказываются на его поведении, приводят к изменению его поведения с целью адаптации к организации, с целью достижения лучшего взаимодействия с организационным окружением.

\section{Научение поведению в организации}

Очевидно, что восприятие и оценка своего опыта, а также процесс адаптации к условиям и требованиям организационного окружения, во многом носят индивидуальный характер. В одной и той же среде люди ведут себя по-разному. У человека как бы имеется две степени свободы $в$ построении своего поведения в организации. С одной стороны, он обладает свободой в выборе форм поведения: принимать или не принимать существующие в организации формы и нормы поведения, с другой - он может принимать или не принимать ценности организации, разделять или не разделять ее цели и философию. В зависимости от того, в какой комбинации сочетаются эти основополагающие составляющие поведения, может быть выделено четыре предельных типа поведения человека в организации.

Первый тип: полностью принимаются ценности и нормы поведения. В этом случае человек старается вести себя таким образом, чтобы своими действиями никак не входить в противоречие с интересами организации. Он искренне старается быть дисциплинированным, выполнять свою роль полностью в соответствии с принятыми в организации нормами и формой поведения. Поэтому результаты действий такого человека в основном зависят от его личных возможностей и способностей и от того, насколько верно определено содержание его роли. Такой тип поведения можно охарактеризовать как поведение преданного и дисциплинированного члена организации.

Bторой mип: человек не приемлет ценностей организации, однако старается вести себя, полностью следуя нормам и формам поведения, принятым в организации. Такого человека можно охарактеризовать как приспособленца. Он делает все правильно и по правилам, но его нельзя считать надежным членом организации, так как он, хотя и является хорошим и исполнительным работником, тем не менее, может в любой момент покинуть организацию или совершить действия, которые могут противоречить интересам организации, но соответствовать его собственным интересам. Например, такой человек с готовностью будет участвовать в забастовке для того, чтобы добиться повышения зарплаты.

Третий тип: человек приемлет ценности организации, но не приемлет существующие в ней нормы поведения. В данном случае человек может порождать много трудностей во взаимоотношениях с коллегами и руководством, он выглядит оригиналом. Однако если организация может позволить себе отказаться от устоявшихся норм поведения применительно к отдельным ее членам и создать состояние свободы выбора форм поведения для таких ее членов, они могут найти свое место в организации и приносить ей пользу.

Четвертый тип: индивид не приемлет ни норм поведения, ни ценностей организации. Это открытый бунтарь который все время входит в противоречие с .организационным окружением и создает конфликтные ситуации. Было бы неверно считать, что такой тип поведения абсолютно неприемлем в организации и люди, ведущие себя таким образом, не нужны организации. Однако в 
большинстве случаев «бунтари» порождают множество проблем, которые существенно усложняют жизнь организации и даже наносят ей большой ущерб.

Естественно, организация заинтересована в том, чтобы ее члены вели себя определенным образом.

Возможный подход к решению данной проблемы - это подбор людей с определенными качествами, которые могут гарантировать желаемое для организации поведение ее членов. Однако следует признать, что данный подход имеет ограниченное применение, так как, вопервых, не всегда можно найти людей с необходимыми характеристиками, во-вторых, нет абсолютной гарантии, что они будут вести себя обязательно таким образом, как этого ожидает организация, и, в-третьих, требования к поведению членов организации со стороны организационного окружения могут меняться во времени, входя в противоречие с теми критериями, по которым люди отбирались в организацию.

Второй подход, в принципе не исключающий первого, состоит в том, что организация влияет на человека, заставляя его модифицировать свое поведение в нужном для нее направлении. Данный подход возможен и базируется на том, что человек обладает способностью обучаться поведению, менять свое поведение на основе осознания своего предыдущего поведенческого опыта и требований, предъявляемых к его поведению со стороны окружения.

Научение поведению можно определить как достаточно устойчивый во времени процесс изменения поведения человека на основе опьта, отражающего действия человека и реакцию окружения на эти действия.

Для научения поведению характерно наличие нескольких моментов.

Bo-nервыl, научение может идти как на собственном опыте, так и на опыте других людей.

Bo-вmopblx, научение поведению не обязательно касается только собственно реального поведения. Оно может касаться потенциального поведения, т.е. такого поведения, которое может быть осуществлено человеком, но которое не осуществляется им в его практике поведения.

B-mpeтьих, научение поведению всегда выражается в изменении человека. Даже в том случае, когда непосредственное поведение не претерпело изменений, человек уже становится другим, так как изменяется его поведенческий потенциал.

Выделяется три типа научения поведению.

Первыц тип связан с рефлекторным поведением человека, с тем, что названо в учении
И. Павлова условным и безусловным рефлексом. Если, например, начальник приходит к подчиненным тогда, когда он чем-то недоволен, раздражен и намерен сделать им выговор, то всякое появление начальника может вызывать страх у подчиненных, желание избежать этой встречи независимо от того, зачем он к ним пришел. То есть появление начальника вырабатывает условный рефлекс желания скрыться с его глаз.

Второй тип научения поведению базируется на том, что человек делает выводы из последствий своего предыдущего опыта, осознанно корректирует и меняет свое поведение. Теоретическое описание данного типа научения в первую очередь опирается на исследования Б. Скиннера, который создал основы теории зацепления осуществленного поведения в зависимости от его последствий. Суть этой теории сводится к тому, что если человек видит, что его поведение приводит к благоприятным последствиям, то он стремится повторять данное поведение, если же последствия оказываются негативными, то желание вести себя и далее аналогичным образом будет существенно понижено. То есть поведение человека задается сознательным осмыслением результатов предыдущего поведения.

Третий тип научения поведению - это обучение на основе наблюдения поведения. Обычно это наблюдение чужого поведения. Человек, регулярно наблюдая, как ведут себя окружающее его люди, автоматически начинает подстраивать к их поведению свое собственное поведение. Он перенимает их стиль и манеры, навыки выполнения операций и т.п. .Часто проводится целенаправленное наблюдение чужого поведения с целью перенять для себя чтото полезное. С развитием средств видеозаписи объекта расширяются возможности наблюдения и, в частности, расширяется, объект наблюдения. Теперь человек может просматривать, записи своего собственного поведения, что также может существенно влиять на корректировку поведения. Очевидно, что все три типа научения поведению должны учитываться руководством организации в его попытках корректировать и формировать поведение членов организации. Не умаляя важности каждого из этих типов научения, тем не менее следует констатировать, что исключительно важную роль в процессе целенаправленного формирования поведения человека в организации играет второй тип научения.

Чему же учится человек в организации, какие стороны его поведения корректируются или меняются в процессе научения?

Bo-nервых, придя в организацию и далее осуществляя свою деятельность в ней, человек 
изучает свою функциональную роль: что он должен делать для лучшего выполнения работы, как осуществлять более эффективно работу, как и с кем коммуницировать в процессе работы. При этом он учится расставлять акценты в выполняемой им работе с точки зрения того, что считается в организации более важным, а что менее важным в его деятельности, за что идет вознаграждение, что входит в оценку качества его работы.

Bo-вmopblx, в организации человек учится выполнению формально-процедурных действий, таких, как заполнение различных анкет и форм, оформление заявок, назначение и, проведение встреч, передача, получение и осуществление ответа на полученную информацию, временное оставление рабочего места, приход и уход с работы, парковка автомобиля, ношение одежды определенного типа и т.д.

$B$-третьих, человек учится правильно понимать и занимать свое место в организации. Он узнает существующие в организации нормы, ценности и сложившиеся на их базе неформальные группы и отношения, учится правильно вести себя с коллегами и руководством, определяет для себя с кем иметь тесные отношения и от кого держаться подальше, кому доверять, на кого полагаться и кого опасаться.

$B$-четвертых, человек учится тому, как решать свои собственные задачи в организации, как добиваться своих целей. Так, например, он учится тому, как делать карьеру в организации. Либо тому, как добиваться определенных поощрений и вознаграждений. Может человек учиться и тому, как использовать возможности организации либо возможности её отдельных членов для того, чтобы решать свои личные задачи, не связанные с деятельностью организации. Работник может учиться тому, как избегать сложных и рискованных заданий, и даже тому, как, ничего не делая, создавать видимость, что он напряженно работает.

Для того чтобы описать процесс сознательного научения человеком поведению в организации и указать на связь этого процесса с управлением человеком в организации, рассмотрим в самых общих чертах несколько основных элементов, определяющих поведение человека в организации. Более подробно эти элементы будут рассмотрены при рассмотрении вопроса мотивации.

Деятельность человека всегда связана и инициируется наличием у него определенных побуждающих начал. Они заставляют его начинать что-то делать, предпринимать какие-то усилия, т.е. осуществлять действия. Стимулы, являющиеся внешними воздействиями на человека, направляют его деятельность в определенное русло, придают этой деятельности определенную ориентацию и границы. Поведенческая реакция человека проявляется в том, что он выбирает, что и как ему делать, и осуществляет конкретные действия, приводящие к конкретному результату. Его реакция сильно связана со стимулами. Однако она имеет индивидуальный характер, так как отражает различную степень влияния стимулов на поведение различных людей. Реакция человека может проявляться как в виде его определенных действий, так и в виде выработки им определенного расположения. В зависимости от последствий для человека его поведенческая реакция закрепляется с целью ее усиления и придания ей устойчивости либо же происходит отказ от нее. Закрепление осуществленного поведения или отказ от него играют очень важную роль в формировании поведения человека, так как именно через это происходит осознанная корректировка или даже изменение поведения человека в желательном для организации направлении.

Таким образом, изменение поведения человека можно рассматривать как следствие научения поведению. Само, же научение поведению является функцией последствий для человека произведенных им действий, функцией последствий его поведения. Наличие такой зависимости между поведением, научением поведению и последствиями для человека его поведения делает возможным для организации корректировать и формировать поведение ее членов. Связано это в первую очередь с тем, что руководство и организационное окружение могут определять и целенаправленно формировать для членов своей организации последствия их поведения, активно включаясь в процесс научения поведению на стадии получения человеком определенных последствий осуществленных действий.

Научение поведению и модификация поведения человека в организации

Очевидно, последствия действий зависят от того, как вел себя человек, что он делал. Однако непосредственно они зависят от тех, кто, оценивая действие человека, осуществляет компенсацию за его действия и усилия. В данном случае компенсация понимается в самом широком смысле как внешняя реакция на поведение человека, выражающаяся в том, что человек либо что-то приобретает, либо что-то теряет, чего-то добивается или же чего-то не достигает в результате осуществленных им в форме определенного поведения действий. 
Компенсация может производиться в различных видах — от материального вознаграждения или наказания до словесного одобрения или осуждения. Компенсация играет исключительно важную роль в научении поведению, так как она оказывает принципиальное влияние на то, происходит ли закрепление осуществленного поведения или же наступает отказ от него. Если отсутствует компенсация, вызывающая у человека представление о последствиях его действий, то фактически не происходит заметной модификации поведения, так как не происходит научения поведению. Поэтому компенсация в управлении людьми играет не только роль вознаграждения за произведенный труд либо роль средства удовлетворения потребностей работников, но и роль средства модификации поведения человека.

Если посмотреть на компенсацию с позиций научения поведению и модификации поведения, то можно выделить четыре различных типа компенсащии, которые приводят к закреплению либо к отказу от осуществленного поведения.

Первый тип - это положительная компенсация. Суть данного типа состоит в том, что осуществляется вознаграждение, приводящее к приятным для человека последствиям. Форма вознаграждения может быть совершенно различной. Позитивная компенсация может быть использована руководством для закрепления желаемого поведения работников. При этом важно принимать во внимание, что вознаграждение должно быть четко привязано к желаемому поведению, т.е. человек должен знать, за что он получил поощрение. Вознаграждение должно следовать за осуществленным желаемым поведением и, наконец, вознаграждение должно соответствовать интересам поощряемого человека.

Второй mип•- это отрицательная компенсация. Суть этого типа состоит в том, что желаемое поведение сразу же приводит к устранению не желаемых для человека обстоятельств или раздражителей. Например, человек, который не ведет себя должным образом, подвергается бойкоту окружающих. Как только он начинает себя вести верно, с точки зрения окружения, они прекращают бойкот. При втором типе компенсации, также как и при первом, важно, чтобы реакция окружения или руководства на изменение поведения наступала по возможности быстрее и, конечно же, носила индивидуальный характер.

Третьим типом компенсации является наказание. В данном случаев отличие от первых двух типов компенсация наступает как реакция на «неверное», нежелательное для руководства или организаций поведение.
Если при первых двух типах закрепляется желательное поведение, то в данном случае устраняется нежелательное поведение. Компенсация в виде наказания состоите том, что человек получает негативные, неприятные для него последствия поведения. Например, он может быть оштрафован, лишиться премии или продвижения по работе, получить замечание и т.п. Задача наказания состоит в том, чтобы сузить или же устранить нежелательное для организации поведение ее членов. Хотя наказание внешне выглядит полной противоположностью положительной компенсации - там награждают, здесь забирают, - с точки зрения научения поведению человека это не так. Данный тип компенсации менее действен, чем положительная компенсация. Это связано с тем, что наказание имеет менее предсказуемый и устойчивый эффект, чем поощрение, зачастую приводит к косвенным негативным последствиям, таким, как личная обида на наказавшего руководителя, потеря интереса к работе, изменение отношения к своей деятельности и т.П. Поэтому к наказанию как способу компенсации с целью научения поведению руководству следует относиться очень осторожно и внимательно отслеживать его возможные побочные негативные проявления.

Четвертый тип компенсации - это гашение нежелательного поведения; Суть данного типа компенсации состоит в следующем. Человек, осуществляющй какие-то нежелательные действия, на которые ранее поступала положительная реакция, через некоторое время прекращает их, если на эти действия перестает поступать положительная реакция, т.е., говоря иначе, если прекратить положительно реагировать на какие-то действия, то через некоторое время они начнут сокращаться. Например, молодой человек, успешно учившийся в университете и получавший похвалу преподавателей за активные выступления на занятиях и за комментарии по поводу выступления своих коллег, придя на работу в организацию, будет также пытаться встревать во все обсуждения и разговоры и давать свои комментарии и оценки заявлениям других. Однако если на это не обращать внимания, то через некоторое время он начнет избавляться от этой дурной привычки. Выбор типа и конкретной формы компенсации играет очень важную роль в деле успешной модификации поведения человека в желаемом для организации направлении.

Однако не менее важную роль играет $и$ выбор частоты компенсации с целью направленного научения поведению. $B$ иелом может быть два подхода $\kappa$ выбору времени компенсаџии. 
Один подход - это компенсация после каждого случая действия человека. Данный подход называется непрерывной компенсацией.

Другой, принципиально отличный подход к выбору времени и частоты компенсации состоит в том, что компенсация наступает не после каждого совершенного действия. Это периодическая компенсация. Хотя между этими двумя подходами есть принципиальная разница, нельзя сказать, какой из них более эффективен, потому что их действенность существенно зависит от ситуации, в которой они применяются. В то же время отмечается, что первый .подход лучше действует в том случае, когда он применяется к новому сотруднику, обучающемуся своей роли в организации. Второй же подход лучше применять тогда, когда организация хочет сделать устойчивым определенное поведение ее члена.

В рамках периодической компенсации выделяется четыре различных типа.

Первый тип•- это компенсация через фиксированный интервал времени. Данный подход страдает тем недостатком, что желательное поведение работников проявляется неравномерно, нарастая в те моменты, когда осуществляется фиксация или компенсация, и уменьшаясь в промежутках между ними.

Второй тип - компенсация через переменный интервал времени. В этом случае интервал между возможной компенсацией и частота компенсации не фиксированы. Такой подход применим не ко всем формам компенсации. Однако он дает лучшие результаты, так как неопределенный момент компенсации держит в напряжении и заставляет лучше работать и вести себя. Хотя после наступления компенсации может произойти резкий спад в желательном для организации поведении ее членов.

Третий тип в отличие от первого и второго за основу берет не временной интервал, а объем действий. Этот тип называется компенсацией в зависимости от фиксированной нормы. При таком подходе компенсация наступает после того, как совершено какое-то фиксированное число действий. Практика показывает, что данный тип компенсации дает лучшие результаты в формировании поведения, чем первый и второй типы периодической компенсации.

Четвертый тип (последний), в основе также имеет компенсацию в| зависимости от объема действий. Однако это компенсация в зависимости от переменной нормы. Данный подход считается высокоэффективным, так как компенсация может наступить после любого отдельного действия, что побуждает работников постоянно осуществлять «правильные» действия.
Для того чтобы этот подход давал по-настоящему высокий результат в модификации поведения, важно, чтобы временные интервалы между компенсацией были не очень большими. В то же время необходимо знать, что данный подход имеет ограниченное использование. Например, он малоприменим к такой форме компенсации, как заработная плата.

Рассмотренные вопросы научения поведению говорят о том, что человек, опираясь на свой опыт, адаптируется к организационному окружению, меняя свое поведение. Организация и ее руководство могут активно воздействовать на модификацию поведения человека. Однако и, средства, используемые для влияния на процесс научения поведению, и частота их использования зависят от ситуации, в которой находится человек, и должны подбираться менеджером с учетом всего многообразия факторов, влияющих на поведение человека. В первую очередь с учетом потребностей и мотивов человека к деятельности.

Процесс мотивации характеризуется четырьмя теориями, создающими основу для мотивации.

Теория ожидания: ожидание в цепочке "усилия исполнения"; ожидание в цепочке "исполнение - результат"; валентность результата.

Теория постановки целей. Четыре характеристики цели: сложность, специфичность, приемлемость, приверженность.

Теория равенства: сравнение своих результатов действий с результатами других.

Концепция партисипативного управления.

Самая общая концепция процесса мотивации сводится к следующим положениям. Человек, осознав задачи и возможное вознаграждение за их решение, соотносит эту информацию со своими потребностями, мотивационной структурой и возможностями, настраивает себя на определённое поведение, вырабатывает определенное расположение и осуществляет действия, приводящие к конкретному результату, характеризующемуся определенными качественными и количественными характеристиками.

Данная схема не раскрывает еще ни механизма вознаграждения, ни собственно содержания вознаграждения, сущности и содержания оценки, ни превращения оценки в решение. В современной управленческой мысли и практике существует ряд теорий, которые достаточно подробно и на операционном уровне описывают процесс мотивации. Наиболее известные из них - это теория ожидания, теория постановки иелей, теория равенства и теория партисипативного управления. Они пытающихся объяснить, почему люди готовы осуществлять определенные 
действия, затрачивая большие или меньшие усилия. И, объясняя это, они дают менеджерам ключ К построению действенной системы мотивирования людей, т. е. как следует воздействовать на людей, чтобы побуждать их к результативной работе.

Поведение человека постоянно связано с выбором из двух иди нескольких альтернатив. От того, чему человек отдает то или иное предпочтение, зависит, что и как он делает, как он себя ведет и каких результатов он добивается. Теория ожидания разработана для того, чтобы дать ответ на вопрос, почему человек делает тот или ивой выбор, сталкиваясь с несколькими альтернативами, и насколько он мотивирован добиваться результата в соответствий, со сделанным выбором. В самом обобщенном виде теорию ожидания можно сформулировать как учение, описывающее зависимость мотивации от двух моментов: как много человек хотел бы получить и насколько возможно для него получить то, что он хотел бы получить, в частности, как много усилий он готов затрачивать для этого. Например, начинающий бизнесмен из провинции приезжает на переговоры о начале совместного бизнеса с представителями крупных фирм, расположенных в городе, являющемся признанным центром деловой активности. Для поддержания своего реноме он не будет останавливаться в гостинице, имеющей репутацию второсортной, хотя и являющейся дешевой. В то же время у него нет средств, чтобы остановиться в шикарной гостинице. Поэтому, по-видимому, он остановится в такой гостинице, которая является достаточно престижной и на проживание в которой у него хватит средств.

Процесс мотивации по теории ожидания складывается как бы из взаимодействия трех блоков: 1) усилия; 2) исполнение; 3) результат. Теория ожидания изучает и описывает взаимодействие этих трех блоков. При этом усилия рассматриваются как следствие, и даже результат мотивации. Исполнение рассматривается как следствие взаимодействия усилий, личных возможностей и состояния среды, а результат, как функция, зависящая от исполнения и, от степени желания получить результаты определенного типа.

Теория ожидания объясняет то, как строится процесс мотивации человека к деятельности, исходя из увязки в единое целое представлений человека о необходимых для выполнения работы усилиях, ее практическом исполнении и результатах, ожидаемых в ответ на выполненную работу. При этом ключевыми точками концентрации внимания теории являются: 1) ожидания по цепочке «усилия - исполнение»; 2) ожидания по цепочке «исполнение - результаты второго уровня и 3) валентность результатов.
В соответствии с теорией ожидания, мотивация человека к исполнению работы зависит от того, насколько он заинтересован или не заинтересован выполнять ее, насколько работа привлекательна для него. Принимая решение по поводу того, что делать и какие усилия затрачивать, человек обычно отвечает самому себе на вопрос, касающийся того, насколько нужно ему это делать. То есть при выборе альтернативы человек думает о том, если он поведет себя соответствующим образом, будет соответствующим образом исполнять работу, приведет ли это к определенному результату первого уровня. В этом случае у него формируется ожидание результата первого уровня. Кроме этого, человек отвечает на вопрос о том, что он получит в результате успешного выполнения работы .

Это уже выработка ожидания результатов второго уровня. И, наконец, он решает для себя, насколько ценным будет для него этот результат, т.е. он оценивает валентность результата второго уровня. В зависимости от того, к какой окончательной оценке человек придет, будет формироваться его мотивация на выполнение работы.

Основные положения теории ожидания состоят в следующем.

Bo-nepbыx, так как данная теория подчинена идее поиска ответа на вопрос, как мотивация влияет на выполнение работы, то исходный постулат состоит в том, что исполнение определяется произведением значений двух факторов: возможности человека и его мотивации.

Bo-вmopblx, утверждается, что мотивация задается произведением величины ожидания результатов первого уровня на величину валентности результатов первого уровня. И, наконец,

6-третьих, валентность результатов первого уровня задается произведением величины валентности результатов второго уровня на ожидания отдельных результатов второго уровня. Человек выбирает ту альтернативу, где будет выше мотивация.

Используя различные приемы, менеджер для успешного управления подчиненными должен построить управление организацией таким образом, чтобы работник был уверен, что, работая на достижение организационных целей, он тем самым создает условия для наилучшего достижения результатов второго уровня.

В теории ожидания считается, что для того, чтобы смог осуществиться процесс мотивирования, должен быть выполнен ряд предварительных условий. Такими условиями являются:

- наличие у работников достаточно высоки степени ожидания результатов первого уровня; 
- наличие достаточно высокой степени ожидания результатов второго уровня и

- суммарная неотрицательная валентность результатов второго уровня.

На практике это означает, что работник должен иметь устойчивое представление о том, что от его усилий зависят результаты его труда, что из результатов его труда вытекают для него определенные последствия, а также то, что результаты, получаемые им, в конечном счете, имеют для него ценность. При отсутствии одного из этих условий процесс мотивирования становится исключительно сложным или же даже неосуществимым.

Делая общий вывод относительно теории ожидания, необходимо отметить, что она исходит из того, что люди осуществляет свои действия в соответствии с тем, к каким возможным последствиям для них эти действия могут привести. Люди на основе доступной им информации делают выбор одной из альтернатив действия, исходя из того, что они получат в результате и какие усилия они должны будут затратить, чтобы достичь этого результата. То есть, по теории ожидания, человек ведет себя в соответствии с тем, что, по его мнению, произойдет в будущем, если он произведет определенные затраты усилий.

Теория постановки целей исходит из того, что поведение человека определяется теми целями, которые он ставит перед собой, так как именно ради достижения поставленных перед собой целей он осуществляет определенные действия. При этом предполагается, что постановка целей это сознательный процесс, а осознанные цели и намерения - это то, что лежит в основе определения поведения человека.

В общей виде базисная модель, описывающая процесс постановки целей, выглядит следующим образом. Человек с учетом эмоциональной реакции осознает и оценивает события, происходящие в окружении. На основе этого он определяет для себя цели, к достижению которых он намерен стремиться, и, исходя из поставленных целей, осуществляет определенные действия - выполняет определенную работу. То есть ведет себя определенным образом, достигает определенного результата и получает от этого удовлетворение.

Теория постановки целей утверждает, что уровень исполнения работы непосредственно или опосредованно в значительной степени зависит от четырех характеристик целей:
$\square$ сложность;
$\square$ специифичность;
$\square$ приемлемость;
$\square$ приверженность.

Эти четыре характеристики цели влияют как собственно на цель, так и на те усилия, которые человек готов затрачивать, чтобы достичь поставленной перед ним цели.
Сложность ияели отражает степень профессиональности и уровень исполнения, необходимый для ее достижения. Существует непосредственная связь между сложностью цели и выполнением работы. Чем сложнее цели ставит перед собой человек, тем лучших результатов он добивается. Исключение составляет тот случай, когда ставятся цели нереалистично высокие, которые в принципе не могут быть достигнуты.В этом случае, как утверждает теория постановки цели, результат действий не превышает результата, которого добиваются те, кто ставил умеренные, но достижимые цели. Поэтому повышение целей, хотя оно и оправданно, может приводить к повышению результатов труда только в том случае, если будет сохраняться шанс достижения ияелей.

Специфичность ичели отражает количественную ясность цели, ее точность и определенность. Экспериментальными исследованиями было установлено, что более конкретные и определенные цели ведут к лучшим результатам, к лучшему исполнению работы, чем цели, имеющие широкий смысл, с нечетко определенным содержанием и границами. Человек, имеюший цели слишком иирокого смысла и содержания, демонстрирует такое же исполнение работы, как и тот, кто совершенно не имеет иелей. В то же время слишком большое сужение целей может привести к тому, что за бортом рассмотрения у человека могут остаться важные аспекты осуществляемой им деятельности. Это также негативно скажется на исполнении им своей работы.

Приемлемость цели отражает степень, до которой человек воспринимает цель как свою собственную. Приемлемость цели оказывает существенное влияние на то, как воздействуют на исполнение работы сложность и специфичность цели. Если человек не приемлет цель, то и сложность и специфичность цели будут иметь очень слабое влияние на исполнение работы. Приемлемость цели человеком напрямую зависит от того, воспринимается ли она им как достижимая, и от того, какие выгоды он может получить при достижении цели. Если выгоды не очевидны, то цель может быть не принята. Поэтому в руководстве организация должно существвовать четкое осознание значимости, важности проведения действий, которые бы делали цель достижимой, выгодной, справедливой и безопасной в представлении работника.

Приверженность ичели отражает готовность затрачивать усилия определенного уровня для достижения цели. Это очень важная для уровня; и качества исполнения характеристика цели, так как она может играть решающую роль на стадии исполнения, если реальность, трудности выполнения работы будут существенно отличаться 
от того, какими они представлялись на стадии постановки цели. Приверженность цели может возрастать по мере исполнения работы, а может и понижаться. Поэтому руководство должно постоянно отслеживать уровень приверженности цели со стороны работников и осуществлять необходимые меры для поддержания ее на должном уровне.

В теории постановки целей при рассмотрении зависимости исполнения от целей подчеркивается, что качество исполнения зависит не только от определяемых целью усилий работника, но и от двух групп факторов: 1) организаичинные факторы и 2) способности работника. При этом данные группы факторов могут влиять не только на качество и содержание исполнения, но и на цели, оказывая тем самым опосредованное влияние на мотивацию и, следовательно, дополнительное влияние на исполнение. Так, например, если в работе слабо присутствует обратная связь от результатов труда, то это может снижать степень влияния цели на усилия работника по выполнению работы.

Последним шагом процесса мотивации в теории постановки цели является удовлетворенность работника результатом. Особое значение данного шага состоит в том, что он не только завершает цепочку процесса мотивации, но и является исходным для осуществления следующего цикла мотивации.

В теории констатируется, что если в результате действий получен позитивный для субъекта результат, то он получает удовлетворение, если негативный - то расстройство. При этом теория постановки цели утверждает, что удовлетворенность или же неудовлетворенность определяется двумя процессами: внутренним по отношению к человеку процессом и внешним.

Внутренние процессы, приводящие к удовлетворенности, в основном связаны с тем, как человек оценивает полученный им результат с точки зрения соотнесения его с поставленной целью. Если цель достигнута, выполнена взятая на себя задача, то человек испытывает чувство удовлетворенности. Если же нет, то это вызывает неудовлетворенность. Данное обстоятельство порождает определенное противоречие в постановке цели. Как уже говорилось, чем выше и сложнее цель, тем выше уровень исполнения. В то же время высокая цель может с большей вероятностью привести к тому, что она не будет достигнута, а, следовательно, человек будет ощущать чувство неудовлетворенности, расстройства. Это в свою очередь может привести к стремлению - брать более низкие цели, отказываться от постановки или принятия сложных целей. Поэтому важно на стадии постановки цели очень серьезно подходить к данной проблеме.
Внешними процессами, влияющими на удовлетворенность или же неудовлетворенность человека достигнутыми результатами, являются процессы реакции на результаты труда со стороны окружения, оценка окружением исполнения. Если окружение позитивно реагирует (благодарность руководства, продвижение по службе, повышение оплаты, похвала коллег и т.п.), то это вызывает удовлетворение, если нет, то приводит к неудовлетворенности.

Внешние процессы также заключают в себе некоторое противоречивое начало, оказывающее двойственное воздействие на поддержание мотивационного процесса в эффективном, с точки зрения качества и уровня исполнения, состоянии. Суть этого противоречия состоит в том, что человек ведет себя в соответствии с поставленными целями, а оценка его действий чаще всего базируется на результатах исполнения. Поэтому, если человек добивается поставленных целей, но при этом демонстрирует невысокий уровень исполнения, умеренная или даже отрицательная внешняя оценка может привести к очень сильному расстройству и резкому падению мотивации к продолжению действия. Так же негативно на мотивационный процесс может повлиять позитивная внешняя оценка успешного исполнения при том условии, что человеку не удалось достичь своих целей. Это приводит к понижению приверженности цели и, в конечном счете, негативно сказывается в дальнейшем на качестве и уровне исполнения работы. Если же внешняя оценка базируется на том, была ли достигнуга цель или нет, то в этом случае также имеются моменты, которые могут ослабить мотивационный процесс человек для гарантированного достижения будет ставить перед собой более простые цели, что обязательно негативно скажется на качестве и уровне исполнения.

Общие рекомендации по осуществлению процесса постановки целей можно свести к следующему.

Первое, необходимо определить, в какой мере организация и люди, в ней работающие, готовы к реализации процесса постановки целей.

Bторое, если у организации есть потенциальная готовность, то необходимо провести ряд мероприятий по практической подготовке введения процесса постановки целей.

Tpeтье, постановка целей должна осуществляться с подчеркиванием их сложности и специфичности и с учетом приемлемости целей и приверженности им.

Четвертое, необходимо проведение промежуточного анализа целей и их корректировки.

Пятое, необходимо проводить анализ достижения целей, обобщение результатов 
предыдущих этапов и выработку рекомендаций по дальнейшему осуществлению процесса постановки целей.

Одним из постоянных стремлений людей является желание получать справедливую оценку своим действиям. Люди, хотя и не в одинаковой степени, желают, чтобы к ним относились справедливо. При этом справедливость связывается с равенством, в сравнении с отношением к другим и оценке их действий. Если человек считает, что к нему подходят так же, как к другим, без дискриминации, оценивают его действия с тех же позиций, что и действия других, то он ощущает справедливость отношения к себе и чувствует себя удовлетворенным. Если же равенство нарушается, если отдельные члены организация получают незаслуженно высокую оценку и вознаграждение, то человек чувствует себя обиженным, и это приводит к расстройству и неудовлетворенности. При этом неудовлетворенность может наступить даже тогда, когда человек получает высокое по отношению к затратам его труда вознаграждение. Влияние данного момента на взаимоотношение человека с организацией положено в основу одной из теорий мотивационного процесса — теории равенства.

Теория равенства исходит из того, что в процессе сравнения, хотя и используется объективная информация, например, величина заработной платы, сравнение осуществляется человеком на основе его личного восприятия и своих действий, и действий людей, с которыми он проводит сравнение.

Норма - отношение воспринятых затрат к воспринятому вознаграждению. Выделяется два типа норм. Норма первого типа отражает соотношение воспринятого вознаграждения индивида к воспринятым затратам индивида. Норма второго типа отражает отношение воспринятого вознаграждения других к воспринятым затратам других.

Теория равенства говорит, что для человека очень важно то, как соотносится его норма с нормой других. Если нормы равны, то человек, даже и при меньшем вознаграждении, ощущает справедливость, так как в данном случае имеется равенство. Если его норма ниже, то он считает, что его вознаграждают недостаточно. Если же его норма выше, то он считает, что его излишне вознаграждают.

Имеющее место в управленческой практике представление, что неравенство подталкивает людей на увеличение исполнительских результатов, что состояние равенства демотивирует людей добиваться больших результатов, в принципе неверно. Как утверждается в теории равенства на основе проведенных эмпирических исследований, человек испытывает чувство удовлетворенности, если соблюдается равенство. Поэтому он стремится к поддержанию этого состояния.

Равенство плохо тогда, когда общий уровень исполнения низок. В этом случае равенство будет приводить к сохранению этого уровня. Если же общий уровень исполнения высок, равенство является важным мотивирующим фактором успешной работь членов организации.

В том случае, если индивид считает, что он вознагражден недостаточно или излишне, у него возникает чувство неудовлетворенности (во втором случае это чувство менее выражено). Считая несправедливой и неравной оценку своего труда, человек теряет мотивацию к активным созидательным, с точки зрения целей организации, действиям, что приводит ко многим негативным последствиям.

Теория равенства позволяет сделать несколько очень важных выводов для практики управления людьми в организации. Так как восприятие носит субъективный характер, очень важно, чтобы была широко доступна информация о том, кто, как, за что и сколько получает вознаграждения. Особенно важно, чтобы существовала ясная система оплаты, отвечающая на вопрос о том, какие факторы определяют величину оплаты. Важным выводом из теории равенства является то, что люди ориентируются на комплексную оценку вознаграждения. Оплата труда играет важную роль в этой комплексной оценке, но далеко не единственную и не обязательно определяющую. Поэтому менеджеры должны это учитывать, если они стараются создавать, атмосферу равенства в коллективе.

Как неоднократно подчеркивалось, восприятие равенства и справедливости носит сильно выраженный субъективный характер. Для успешного управления людьми менеджер должен не только стремиться быть справедливым, создавать атмосферу равенства, но и хорошо знать, считают ли работники, что вознаграждение строится на равной и справедливой основе. Для этого руководство должно регулярно проводить исследования с целью выяснения, как оценивается вознаграждение работниками, считают ли они его равным или нет.

Человек в организации проявляет себя не только как исполнитель определенной работы или определенной функции. Он проявляет заинтересованность в том, как организована его работа, в каких условиях он работает, в том, как его работа сказывается на деятельности организации. То есть у него имеется естественное стремление участвовать в протекающих в организации процессах, которые связаны с его деятельностью в организации, но при этом выходят за рамки его компетенции, за рамки выполняемой им работы и решаемых им задач. 
Концепция партисипативного управления исходит из того, что если человек в организации заинтересованно принимает участие в различной внутриорганизационной деятельности, то он тем самым, получая от этого удовлетворение, работает с большей отдачей, лучше, более качественно и производительно. Bo-nервыl, считается, что партисипативное управление, открывая работнику доступ к принятию решения по поводу вопросов, связанных с его функционированием в организации, мотивирует человека к лучшему выполнению своей работы. Вовторых, партисипативное управление не только способствует тому, что работник лучше справляется со своей работой, но и приводит к большей отдаче, большему вкладу отдельного работника в жизнь организации, т.е. происходит более полное задействование потенциала человеческих ресурсов организации.

Первоначально

распространение партисипативного управления связывалось только с улучшением мотивации работников. В последнее же время партисипативное управление все более связывается с улучшением использования всего потенциала человеческих ресурсов организации. Поэтому концепцию партисипативногр управления уже нельзя связывать только с процессом мотивации, а следует рассматривать как один из общих подходов к управлению человеком в организации.

Партисипативное управление может быть реализовано по следующим направлениям.

Bo-nервых, работники получают право самостоятельно принимать решения по поводу того, как им осуществлять свою деятельность. Самостоятельность может касаться, например, таких аспектов их деятельности, как режим работы илй выбор средств осуществления работы.

Bo-вторых, работники могут привлекаться к принятию решения по поводу выполняемой ими работы. В этом случае руководитель советуется с работником по поводу того, что ему делать и как выполнять поставленные перед ним задачи. То есть, говоря иначе, работник привлекается к постановке целей, которые ему предстоит достигать, определению задач, которые ему придется решать.

$B$-третьих, работникам дается право контроля над качеством и количеством осуществляемого ими труда и соответственно устанавливается ответственность за конечный результат.

$B$-четвертых, партисипативное управление предполагает широкое участие работников в рационализаторской деятельности, в вынесении предложений по совершенствованию их собственной работы и работы организации в целом, а также ее отдельных подразделений.
B-nятых, возможным направлением осуществления партисипативного управления является предоставление работникам права на формирование рабочих групп из тех членов организации, с которыми им хотелось бы работать вместе. В этом случае дается право принятия решения не только по поводу собственной работы члена организации, но и по поводу того, с кем кооперироваться в групповой деятельности.

В реальной практике все эти направления осуществления партисипативного управления обычно используются в определенной комбинации, так как они очень тесно связаны друг с другом и очень хорошо дополняют друг друга. Более того, именно в комбинации друг с другом эти отдельные направления могут эффективно проявить себя, и именно отдельные устоявшиеся комбинации этих направлений используются как конкретные формы партисипативного управления. Наиболее наглядным примером этого являются кружки качества, широко используемые в управлении японскими фирмами. 


\begin{tabular}{|c|c|c|c|c|c|c|}
\hline Impact Factor: & $\begin{array}{l}\text { ISRA (India) } \\
\text { ISI (Dubai, UAE } \\
\text { GIF (Australia) } \\
\text { JIF }\end{array}$ & $\begin{array}{l}=1.344 \\
=0.829 \\
=0.564 \\
=1.500\end{array}$ & $\begin{array}{l}\text { SIS (USA) } \\
\text { PИНЦ (Russia) } \\
\text { ESJI (KZ) } \\
\text { SJIF (Morocco) }\end{array}$ & $\begin{array}{l}=0.912 \\
=0.207 \\
=4.102 \\
=\mathbf{2 . 0 3 1}\end{array}$ & $\begin{array}{l}\text { ICV (Poland) } \\
\text { PIF (India) } \\
\text { IBI (India) }\end{array}$ & $\begin{array}{l}=6.630 \\
=1.940 \\
=4.260\end{array}$ \\
\hline
\end{tabular}

\section{Заключение}

Человек осуществляет определенные действия в соответствии с давлением на него совокупности внутренних и внешних по отношению к нему сил. Совокупность этих сил, называемая мотивацией, вызывает у людей далеко не одинаковую реакцию. Поэтому невозможно однозначно описать процесс мотивации. В то же время на основе эмпирических исследований было разработано несколько концепций, описывающих факторы, влияющие на мотивацию и содержание процесса мотивации.

Так называемые теории содержания мотивации основное внимание уделяют тому, как различные группы потребностей оказывают влияние на поведение человека. Широко признанными концепциями этой группы являются теория иерархии потребностей Маслоу, теория ERG Альдерфера, теория двух факторов Герцберга и теория приобретенных потребностей МакКлелланда. Несмотря на принципиальные отличия этих концепций, они тем не менее имеют нечто общее в своей основе, что отражает определенную общность в мотивации человека к действиям.

Процесс мотивации раскрывается в теориях, пытающихся объяснить, почему люди готовы осуществлять определенные действия, затрачивая большие или меньшие усилия. Теория ожидания, теория постановки целей, теория равенства и теория партисипативного управления, объясняя то, как следует воздействовать на людей, чтобы побуждать их к результативной работе, дают менеджерам ключ к построению действенной системы мотивирования людей.

\section{References:}

1. (2017) The concept of import substitution of products of light industry: background, challenges, and innovations: monograph / V. Prokhorov, T.[and others]; under the General editorship of Dr. sci. Sciences, Professor V. T. Prokhorov; the Institute of service sector and entrepreneurship (branch) don state technical University.- Mine: Isop (branch) DGTU, 2017. $-334 \mathrm{p}$.

2. (2015) Advertising as a tool of prodvijenie philosophy of quality of production of competitive products/ Kononenko E. V., [et al.]; under the General editorship of doctor of technical Sciences, Professor V. T. Prokhorov; the Institute of service sector and entrepreneurship (branch) don state technical University Shakhty: ISO and P (branch) DGTU, 2015, - p. 623.

3. (2014) The quality revolution: through the ad or through a quality real: monograph V. T. Prokhorov [et al.]; under the General editorship of doctor of technical Sciences, Professor V. T. Prokhorov; VoIP (branch) of DSTU. Novocherkassk: URGU (NPI), 2014. - 384 p.

4. (2015) The range and assortment policy: monograph / T. V. Prokhorov, T. M. Osina, E.
V., Kononenko [et al.]; under the General editorship of Dr. sci. Sciences, Professor V. T. Prokhorov, Institute of the service sector and entrepreneurship (Phil.) Feder. the state budgets. obrazovat. companies higher. professional education "don state technical. Univ" in Shakhty Growth. region. (Isoip (branch) DGTU). - Novocherkassk: URGU (NPI), 2015. - p. 503.

5. Prokhorov V. T., Osina T. M., Reva D. V., Duyun L. V., Zverev S. M. (2015) influence Of product concepts on the performance of footwear enterprises in the regions of SFD and NCFD (message 1) // Scientific almanac. 2015. No. 7 (9). P. 740-753. 201

6. Prokhorov V. T., Osina T. M., Reva D. V., Duyun L. V., Zverev S. M. (2015) influence Of product concepts on the performance of footwear enterprises in the regions of SFD and NCFD (message 2) // Scientific almanac. 2015. No. 7 (9). S. 754-767.

7. Reva D. V., Prokhorov V. T., Mishin Y. D., Korablina S. Y., Osina T. M., Tikhonov N. In. (2016) What action needs to be the most effective to their implementation provoked to restore credibility to the domestic light 
industry// "New technologies and materials of light industry" - XII international scientificpractical conference with elements of scientific school for students and young scientists: Collection of articles. - Kazan, KAZAN technological University, 2016 - p. 45-52.

8. (2008) Quality management of competitive and in-demand materials and products: Monograph / Yu. Mishin [et al.]; under the General editorship of doctor of technical Sciences, Professor V. T. Prokhorov.- Mine: Publishing house GOU VPO yurgues, 2008. - 654 p.

9. (2012) Managing production of competitive products in demand: / V. T. Prokhorov [et al.]; under the General editorship of doctor of technical Sciences, Professor V. T. Prokhorov; VPO yurgues. - Novocherkassk: yurgtu (NPI), 2012. - $280 \mathrm{p}$.

10. Evseeva, K. G., Davtyan, G. G., Prokhorov V. T., Osina T. M., Tikhonov N. In. Korablina S. Y. (2016) the search for effective segmentation of the domestic market of the SFD and skfo relevant and competitive shoes //Leather and fur in XXI century: technology, quality, ecology, education: proceedings of the XII International scientific-practical conference. - Ulan-Ude: publishing house of ESSUTM,2016. - S. 312320

11. Davtyan, G. G., Prokhorov V. T., Osina T. M., Reva V. D., Korablina S. Volkova, G. Yu., Tikhonov N. In. (2016) About the possibilities of the assortment policy of import substitution in the regions of SFD and NCFD competitive and popular shoes / Integration of Russian science into the world: structural transformations and perspective directions of development, 30-31 may 2016, SaintPetersburg. SPb.: Izd-vo "Kultinformpress", 2016. - p. 65-69

12. Davtyan, G. G., Prokhorov V. T., Osina T. M., Reva V. D., Korablina S. Volkova, G. Yu., Tikhonov N. In. (2016) Possible product concepts for import substitution of products thanks to the industry of regions of the SFD and skfo/ Integration of Russian science into the world: structural transformations and perspective directions of development, 30-31 may 2016, Saint-Petersburg. SPb.: Izd-vo "Kultinformpress", 2016. - p. 69 to 76

13. Reva D. V., Davtian, G. G., Korablina S. Yu., Prokhorov V. T., Osina T. M., Tikhonov N. In. (2016) On the possibility of randomization to a reasonable segmentation of the domestic markets of the regions of SFD and NCFD children's shoes //Leather and fur in XXI century: technology, quality, ecology, education: proceedings of the XII International scientific-practical conference. - Ulan-Ude: publishing house of ESSUTM,2016. - p. 327335.

14. Reva D. V., Davtian, G. G., Korablina S. Yu., Prokhorov V. T., Osina T. M., Tikhonov N. In (2016) On the impact of product policy and innovative solutions in the production of import-substituting shoes for consumers in the regions of SFD and NCFD //Leather and fur in XXI century: technology, quality, ecology, education: proceedings of the XII International scientific-practical conference. - Ulan-Ude: publishing house of ESSUTM,2016. - p. 374

15. Reva D. V., Davtian, G. G., Korablina S. Yu., Prokhorov V. T., Osina T. M., Tikhonov N. (2016) The Possibility of assortment policy on the market segmentation of regions of SFD and NCFD shoes for import-substituting consumer //Leather and fur in XXI century: technology, quality, ecology, education: proceedings of the XII International scientific-practical conference. - Ulan-Ude: publishing house of ESSUTM,2016. - p. 390-397

16. Zagrebelny S. A., Prokhorov V. T., Osina T. M., Korablina S. Volkova, G. Yu., Tikhonov N. In. (2016) About the possibilities of the innovative solutions in import substitution of products thanks to the industry of regions of the SFD and skfo/ Integration of Russian science into the world: structural transformations and perspective directions of development, 30-31 may 2016, Saint-Petersburg. SPb.: Izd-vo "Kultinformpress", 2016. - p. 107-114

17. Zagrebelny S. A., Prokhorov V. T., Osina T. M., Korablina S. Volkova, G. Yu., Tikhonov N. In. (2016) On features of formation of competitiveness of regions of SFD and NCFD is based on the concept of their partnership/ Integration of Russian science into the world: structural transformations and perspective directions of development, 30-31 may 2016, Saint-Petersburg. $\quad$ SPb.: Izd-vo "Kultinformpress", 2016. - p. 114-123

18. Getmanova, E. F., S. Y. Korablina V. T. Prokhorov, T. M., ASP, N. In. Tikhonova, I. S. (2016) Shrivel import Substitution footwear at the expense of informed decision assortment policy to ensure consumers popular shoes// II international scientific and practical conference "Models of innovative development of textile and light industry based on the integration of University science and industry. Educationscience-production": collection of articles. 2325 March 2016; M-in the way. and science of Russia, Kazan. NAT. issled. tekhnol. Univ. of Illinois - Kazan: Publishing house of KAZAN state technical University, 2016. - p. 335-341

19. K. G. Evseeva, S. Y. Korablina V. T. Prokhorov, L. N. Rezvanova N. Tikhonov (2016) About the benefits of innovative 


\begin{tabular}{l|lr|ll|ll} 
& ISRA (India) & $=\mathbf{1 . 3 4 4}$ & SIS (USA) & $=\mathbf{0 . 9 1 2}$ & ICV (Poland) & $=\mathbf{6 . 6 3 0}$ \\
Impact Factor: & ISI (Dubai, UAE) $=\mathbf{0 . 8 2 9}$ & PUHL (Russia) $=\mathbf{0 . 2 0 7}$ & PIF (India) & $=\mathbf{1 . 9 4 0}$ \\
& GIIF (Australia) & $=\mathbf{0 . 5 6 4}$ & ESJI (KZ) & $=4.102$ & IBI (India) & $=\mathbf{4 . 2 6 0}$ \\
& JIF & $=1.500$ & SJIF (Morocco) & $=2.031$ & & \\
\hline
\end{tabular}

technologies to segment markets competitive and popular shoes// II international scientific and practical conference "Models of innovative development of textile and light industry based on the integration of University science and industry. Education-science-production": collection of articles. 23-25 March 2016; M-in the way. and science of Russia, Kazan. NAT. issled. tekhnol. Univ. of Illinois - Kazan: Publishing house of KAZAN state technical University, 2016.- p 341-349
20. (2017) The concept of import substitution of products of light industry: background, challenges, and innovations : monograph / V. Prokhorov, T.[and others]; under the General editorship of Dr. sci. Sciences, Professor V. T. Prokhorov; the Institute of service sector and entrepreneurship (branch) don state technical University.- Mine: Isop (branch) DGTU, 2017. $-334 \mathrm{p}$. 